\title{
Relationship between generic and occupation-specific job demands and resources, negative work-home interference and burnout among GPs
}

\author{
N.C. Verhoef ${ }^{1 \star}$ (D), M. De Ruiter ${ }^{2}$, R.J. Blomme ${ }^{1,2}$ and E.C. Curfs ${ }^{1}$ \\ ${ }^{1}$ Open University, Heerlen, the Netherlands and ${ }^{2}$ Nyenrode Business University, Breukelen, The Netherlands \\ *Corresponding author. E-mail: nico.phoenix@planet.nl
}

(Received 1 March 2020; revised 7 March 2021; accepted 19 April 2021)

\begin{abstract}
Scholars often examine the effect of generic job demands and resources on burnout, yet to increase ecological validity, it is important to examine the effects of occupation-specific characteristics. An extended version of the job demands-resources model with work-home interference as a mediator is examined among a cross-sectional sample of 178 general practitioners (GPs). Interviews with GPs were used to develop questions on occupation-specific work characteristics. Hypotheses were tested in MEDIATE. Both generic and occupation-specific job demands positively affected emotional exhaustion, while only occupation-specific job demands affected depersonalization. Only strain-based work-family interference mediated the relationship between generic and occupation-specific job demands, emotional exhaustion and depersonalization. This study offers an important extension of the job demands-resources model by including occupation-specific job characteristics. This broader perspective can aid in more targeted job design to reduce burnout among GPs.
\end{abstract}

Key words: human resource management (HRM); job design; qualitative methods; quantitative methods; resources and capabilities; work-family conflict

\section{Introduction}

Scholars often examine the effect of generic job demands on burnout, however, professionals also experience demands specific to their occupation (Brough \& Biggs, 2015; De Croon, Blonk, De Zwart, Frings-Dresen, \& Broersen, 2002; Sundin, Hochwälder, \& Lisspers, 2011). To increase the ecological validity of a study, it is therefore important to also examine the effects of occupation-specific demands and resources (Brough \& Biggs, 2015). For example, a study among correctional workers showed that generic demands were associated with engagement, while occupation-specific demands were associated with both engagement and psychological strain (Brough \& Biggs, 2015). Moreover, Sundin, Hochwälder, and Lisspers (2011) found that one of four occupation-specific demands is linked to emotional exhaustion among nurses. Though not all occupation-specific demands are related to well-being, studies point to an important role of at least some occupation-specific demands. Several studies (Abrahams, Houkes, Winants, Twellaar, \& Verdonk, 2013; Kushnir, Greenberg, Madjar, Hadari, Yermiahu, \& Bachner, 2013; Torppa, Kuikka, Nevalainen, \& Pitkälä, 2015) examined the antecedents of burnout among general practitioners (GPs). However, while these studies examined the role of generic job characteristics such as work pressure (demand) and job control (resource), they generally failed to consider the role of occupation-specific job demands and resources (an exception 
includes Bakker, Schaufeli, Sixma, Bosveld, and Van Dierendonck (2000)). Although Bakker et al. (2000) found that demanding patients (a GP-specific job demand) are connected to emotional exhaustion through perceptions of a lack of reciprocity, they did not examine the effects of both occupation-specific and generic demands. Yet, by excluding either occupation-specific or generic demands and resources, important information is overlooked. To effectively reduce burnout, it is important to examine what type of demands (occupation-specific or generic) play a particularly important role. In the present study, these relationships are examined through an extended version of the job demands-resources (JD-R) model, which includes both generic and occupation-specific characteristics. To better understand why generic and occupationspecific work characteristics affect burnout, this study examines the mediating role of strain-based and time-based negative work-home interference (WHI).

A number of changes have taken place in the past 50 years that have contributed to major changes in the work and home domain (Barnett, 2005; Kossek, Baltes, \& Matthews, 2011). First, coinciding with economic globalization, the nature of the work has changed, particularly in emotionally and mentally demanding jobs (Guest, 2002). Economic globalization is defined by commodity markets, labour markets and capital markets (International Labour Organization, 2016). It includes cross border mobility of goods, services, capital and labour (Korpi \& Tåhlin, 2011). However, as the economy becomes global, competition increases in the battle for market shares and survival. Simultaneously two processes are set in motion by globalization, that is downsizing and restructuring of work with increasing pressure on workers (Hoel, Sparks, \& Cooper, 2001). Moreover, pressures of work have been intensifying by factors such as advances in information technology and information load, the need for speed of response, the importance of quality of customer service and the pace of change. These all demand our time and can be sources of pressure (Guest, 2002; Singh \& Kumar, 2011). Second, a growing number of women have joined the workforce (Fernández \& Wong, 2014; Kossek, Baltes, \& Matthews, 2011; Thijs, Te Grotenhuis, Scheepers, \& Van Den Brink, 2019) which is also the case among GPs (Van Der Velden \& Batenburg, 2017). In 2006, approximately one-third of GPs in the Netherlands were female compared to approximately $50 \%$ in 2016 (Van Der Velden \& Batenburg, 2017). Therefore, balancing work and home life has become an increasingly difficult and growing challenge (Kossek, Baltes, \& Matthews, 2011; Mcnall, Nicklin, \& Masuda, 2010; Michel, Kotrba, Mitchelson, Clark, \& Baltes, 2011). When the work and home domain pressures are mutually incompatible, negative WHI occurs (Amstad, Meier, Fasel, Elfering, \& Semmer, 2011; Bellavia \& Frone, 2005). Responding to recent calls for research (e.g., Bakker, Ten Brummelhuis, Prins, and Van Der Heijden (2011), this study distinguishes between time-based and strain-based negative WHI (Derks, Van Duin, Tims, \& Bakker, 2015; Greenhaus $\&$ Beutell, 1985). Time-based interference occurs when time devoted to one domain makes it difficult to fulfil the other domain's expectations. Strain-based interference is experienced when fatigue or strain produced in one domain affects a person's performance in the other domain (Greenhaus \& Beutell, 1985). It is essential to make this distinction as 'time' and 'strain' are fundamentally different entities that 'are statistically distinct and demonstrate specific relations with antecedents and outcomes' (Van Steenbergen, Ellemers, \& Mooijaart, 2007, p. 280). Although negative WHI has shown to be a significant predictor of burnout (Derks \& Bakker, 2014; Koekemoer \& Mostert, 2006; Linzer, Visser, Oort, Smets, Mcmurray, \& De Haes, 2001), it is unclear whether strain or timebased negative WHI is more critical in the development of burnout.

This study aims to make several significant contributions to the literature. First, by focusing on both generic and occupation-specific demands and resources, this study aims to enhance the JD-R model's ecological validity. Moreover, by including occupation-specific demands, this study aims to enhance the understanding of the types of demands that play the most crucial role in developing burnout among GPs. In addition, we aim to enhance the understanding of the role of negative WHI by considering time and strain-based negative WHI as separate constructs. By examining their roles separately, we hope to gain a better understanding of the type of WHI that is most prominent in the development of burnout among GPs. 


\section{Theoretical background}

\section{Burnout}

Burnout refers to a psychological syndrome originally characterized by the trias emotional exhaustion, depersonalization and reduced personal accomplishment (Maslach, Jackson, \& Leiter, 2001). Emotional exhaustion refers to feelings of exhaustion by the demands of the job (Maslach \& Leiter, 2016a). Depersonalization refers to a negative detachment from work (Maslach \& Leiter, 2016b). Reduced personal accomplishment refers to the self-evaluation of no longer being effective in fulfilling the responsibilities belonging to the job (Freudenberger \& Richelson, 1980). Over the years, there has been much debate about the main components of burnout (Kristensen, Borritz, Villadsen, \& Christensen, 2005; Schaufeli \& Taris, 2005). While some argue for a three-dimensional structure (Cropanzano, Rupp, \& Byrne, 2003; Green, Walkey, \& Taylor, 1991; Lee \& Ashforth, 1996; West, Dyrbye, \& Shanafelt, 2018), others propose there are two main dimensions (emotional exhaustion and depersonalization) that are much stronger correlated with each other than with reduced personal accomplishment (Lee \& Ashforth, 1996). Moreover, it is argued that reduced personal accomplishment more closely resembles an individual difference characteristic than a burnout component (Cordes \& Dougherty, 1993; Shirom, 2003). In the present study, burnout is composed of its two main components, emotional exhaustion and depersonalization.

The JD-R framework can be used to identify the causes of burnout. JD-R theory was first introduced in the scientific literature in 2001 (Demerouti, Bakker, Nachreiner, \& Schaufeli, 2001) and owes its popularity to its flexibility (Schaufeli \& Taris, 2014). The JD-R model's central assumption is that each occupation is associated with two broad types of work characteristics, demands and resources. It is an overarching model which can be applied to many occupations including that of GPs. Job demands are defined as aspects of the work that require sustained physical or cognitive effort (Demerouti et al., 2001). Resources are defined as those objects, personal characteristics, conditions, or energies that are valued by the individual or that serve as a means for the attainment of these objects, personal characteristics, conditions, or energies (Hobfoll, 1989). With regard to burnout, the JD-R model postulates that job demands from which employees do not adequately recover may lead to sustained activation of the autonomic nervous system resulting in negatively valued health problems such as burnout, depression and cardiovascular diseases (Melamed, Shirom, Toker, Berliner, \& Shapira, 2006). In a meta-analytic study, Crawford, Lepine, and Rich (2010) showed that while job demands are positively linked to burnout, job resources negatively affect burnout. The JD-R model is a descriptive model. Although it specifies the relationships between demands, resources and burnout, it does not provide an underlying psychological explanation (Schaufeli \& Taris, 2014). Therefore, scholars use other theories to help explain why demands are positively related to burnout, while resources negatively affect burnout. In the following sections, we draw from Hobfoll's (1989) conservation of resources theory (COR) and from physiological stress theory (Selye, 1950) to explain the expected relationships between demands, resources and burnout.

\section{Job demands and burnout}

According to existing research, GPs are confronted with generic demands such as high workload (Van Den Berg et al., 2009; Zantinge, Verhaak, \& Bensing, 2005) and mental pressure (Croxson, Ashdown, \& Hobbs, 2017; Iacobucci, 2014). In addition, there are several demands related to the GP's specific occupation that require sustained effort. Traditionally, stressors or job demands among GPs are related to the emotionally charged relationship with patients (Van Dierendonck, Schaufeli, \& Sixma, 1994). The demanding nature of the doctor-patient relationship has been regarded as a root-cause of burnout (Maslach, 1978). Repeated confrontation with demanding patients over a prolonged period of time causes perceptions of inequity or lack of reciprocity, depleting emotional resources and initiating the onset of burnout (Bakker et al., 2000). 
Although Bakker et al. (2000) investigated the relationship between demanding patients and emotional exhaustion, this is likely only a limited demanding aspect of the GP's work. Van Ham (2006) presented a number of occupation-specific characteristics such as out of hours services or locum (locum tenens physician) that are also likely to affect burnout. However, such characteristics have not been examined in relation to burnout among GPs.

The expected relationship between job demands, depersonalization and emotional exhaustion will be explained, drawing from physiological stress theory. The general adaptation syndrome (GAS) consists of three phases, the alarm phase, the resistance phase and the exhaustion phase. Noxious agents invoke this syndrome, later called stress (Selye, 1936). After the initial alarm phase, the organism in the resistance phase reacts by increased glucocorticoid production due to this intensifying the systemic response. If the stressor persists, the chemical resources will gradually deplete (Fink, 2017; Selye, 1950). Depleting resources lead to the final phase of recovery or exhaustion. When the bodily compensation mechanisms have successfully overcome the stressor effect, homeostasis or recovery will occur. However, if the stressor persists and compensation mechanisms fail, bodily biochemical resources will become depleted. Whilst unable to function normally, the body will react with serious illnesses such as angina pectoris and clinical depression and other mental illnesses (Fink, 2017; Selye, 1950; Shirom, Toker, Shapira, Berliner, \& Melamed, 2005). While stress refers to the organism's response to noxious agents or stressors, psychological stress refers to the emotional and physiological reactions experienced when an individual is confronted with a situation in which the demands go beyond their coping resources (Folkman, 2013). Occupational stress, in turn, is psychological stress related to one's job. It stems from pressures that do not align with knowledge, skills or expectations (Barron, 2019). Although it is essential to consider individual differences in personality and coping skills, evidence suggests that certain working conditions are stressful to most people (Paoli \& Merllié, 2005). Examples of these stressful working conditions are workload (Katz \& Kahn, 1978), long hours, status, economic factors, bullying (Colligan \& Higgins, 2006), narcissism and psychopathology (Boddy, 2011), workplace conflicts (Keenan \& Newton, 1985), sexual harassment (Gyllensten \& Palmer, 2005) and occupational groups. Stressful working conditions can lead to three types of strain, behavioural (withdrawal behaviour such as absenteeism and poor performance), physical (e.g. headaches and fatigue) and psychological strain (e.g. anxiety or depressed mood) (Burns, Butterworth, \& Anstey, 2016). If exposure to stressors in the workplace is prolonged, chronic health problems may occur, including cardiovascular diseases and burnout (Naghieh, Montgomery, Bonell, Thompson, \& Aber, 2015; Taris, Schreurs, \& Van Iersel-Van Silfhout, 2001).

In summary, job stress can, in the long term, through the general adaptation system, lead to emotional exhaustion and depersonalization. Moreover, the relationship between job demands, emotional exhaustion and depersonalization is empirically well documented (Cordes \& Dougherty, 1993; Lee \& Ashforth, 1996). Hence, we propose the following:

Hypothesis 1: Generic job demands are positively related to (a) emotional exhaustion and (b) depersonalization.

Hypothesis 2: GP-specific job demands are positively related to (a) emotional exhaustion and (b) depersonalization.

\section{Job resources and burnout}

Generic resources have been studied extensively in the academic literature (Schaufeli \& Taris, 2014), while occupation-specific job resources have hardly received any attention (cf. Brough and Biggs, 2015). Existing work has shown that generic job resources such as social support, low job control and performance feedback are related to a wide range of withdrawal reactions such as reduced organizational commitment, turnover and alienation (Barling, Christie, \& 
Hoption, 2010; Buunk, De Jonge, Ybema, \& De Wolff, 1998; Kahn \& Byosiere, 1992). When the external environment lacks resources, individuals can no longer cope with environmental demands such as high workload. In this situation, withdrawal from work is an important selfprotection mechanism that can ultimately lead to depersonalization (Demerouti et al., 2001). These considerations and findings suggest a direct relationship between job resources and depersonalization (Crawford, Lepine, \& Rich, 2010; Demerouti et al., 2001; Hobfoll, 1989; Hobfoll \& Shirom, 1993; Lee \& Ashforth, 1996). The direct relationship between generic job resources and emotional exhaustion and depersonalization is supported in the academic literature (Bakker, Verbeke, \& Demerouti, 2004; Demerouti et al., 2001). In the current study, we use three different generic job resources, namely, performance feedback (Hackman \& Oldham, 1975), collaboration (Montgomery, Spânu, Băban, \& Panagopoulou, 2015) and opportunity for personal development (Van Ruysseveldt, Verboon, \& Smulders, 2011).

According to COR theory, people seek to obtain, retain and protect resources, either instrumentally (e.g. shelter), socially (e.g. social support) or psychologically (e.g. self-esteem). COR theory implies that stress is a reaction to an environment in which there is a threat of loss of resources or an actual loss of resources. Even the lack of an expected gain of resources causes stress (Hobfoll, 1989; Hobfoll \& Shirom, 1993). COR theory distinguishes four types of resources, namely objects (e.g. a house), conditions (e.g. social support from a colleague), personal characteristics (e.g. self-efficacy) and energy (e.g. money) (Hobfoll, 2002). Resources are those entities that either are centrally valued in their own right (e.g. self-esteem, close attachments, health and inner peace) or act as a means to obtain centrally valued ends (e.g. money, social support and credit) (Hobfoll, 2002). Resources can be derived from the organization (e.g., pay), interpersonal and social relations (e.g., supervisor and co-worker support), collaboration (Rabidoux \& Rottmann, 2017; Swensen, Kabcenell, \& Shanafelt, 2016), organization of work (e.g., participation in decision making) and the task (e.g., performance feedback) (Bakker \& Demerouti, 2007; Demerouti et al., 2001; Van Emmerik, Bakker, \& Euwema, 2004). Job resources may be intrinsically motivating by fostering personal growth and development or they may be extrinsically motivating because they allow employees to achieve their work goals. Thus, job resources are predicted to have a direct negative relationship with emotional exhaustion and disengagement (depersonalization) (Bakker \& Demerouti, 2007; Crawford, Lepine, \& Rich, 2010; Demerouti et al., 2001). Hence, the following relationships are hypothesized:

Hypothesis 3: Generic job resources are negatively related to (a) emotional exhaustion and (b) depersonalization.

Hypothesis 4: GP-specific resources are negatively related to (a) emotional exhaustion and (b) depersonalization.

\section{The mediating role of negative work-home interference}

According to Meyman's effort-recovery model (1998), high workload and developing mental or emotional strain is not necessarily unhealthy as long as there is an opportunity for recovery (Meijman \& Mulder, 1998; Van Veldhoven, Houdmont, \& Leka, 2008). However, when limited time and limited energy resources are further depleted by concomitant high home demands (Geurts, Rutte, \& Peeters, 1999), serious conflict in both the work and home domain may occur. In that case, negative WHI is experienced (Greenhaus \& Beutell, 1985). These conflicts may be time-based in a way that time makes it impossible to combine work and home responsibilities (e.g., working overtime and taking care of a child at the same time) (Allen, Herst, Bruck, \& Sutton, 2000). These conflicts may also be strain-based when strain-effects built up during the working period, spill over to the home domain (Greenhaus \& Beutell, 1985; Kopelman, Greenhaus, \& Connolly, 1983). Spillover is the transference of states of well-being from the 
work to the home domain and vice versa (Staines, 1980). Insufficient recovery from the incompatible pressures within the home and work domain is likely to result in psychological health complaints that eventually may increase and lead to emotional exhaustion when strain dominates (Demerouti, Bakker, Geurts, \& Taris, 2009). However, when a lack of resources dominates it is likely that in the long run depersonalization may occur. It is expected that a positive relationship exists between negative WHI (time-based or strain-based) and emotional exhaustion and depersonalization. It is also expected that a positive relationship between job demands and negative WHI exists.

The role of negative WHI as a mediator between work-related demands and burnout has been supported empirically by a substantial number of studies (Bacharach, Bamberger, \& Conley, 1991; Geurts, Kompier, Roxburgh, \& Houtman, 2003; Geurts, Rutte, \& Peeters, 1999; Janssen, Peeters, De Jonge, Houkes, \& Tummers, 2004; Kinnunen \& Mauno, 1998; Lingard \& Francis, 2005; Lu, Wang, Siu, Lu, \& Du, 2015; Montgomery, Panagopolou, \& Benos, 2005, 2006; Parasuraman, Purohit, Godshalk, \& Beutell, 1996). Montgomery, Panagopolou, and Benos (2005) conducted a study among Greek doctors and found that negative WHI partially mediated the relationship between job demands and emotional exhaustion and also that the relationship between emotional job demands and depersonalization was partially mediated by negative WHI. Similar results were found by Geurts, Rutte, and Peeters (1999) in a study among medical residents. Geurts, Rutte, and Peeters (1999) suggested that insufficient recovery from incompatible pressures in the work domain and the home domain (i.e. negative WHI) leads to chronic psychological health problems (e.g., burnout). Hence, it is suggested that high job demands can lead to high negative WHI and high negative WHI, in turn, leads to burnout.

In conclusion, there is theoretical and empirical evidence for the mediating role of strain-based and time-based negative WHI between job demands and burnout. We, therefore, propose the following hypotheses:

Hypothesis 5: Time-based negative WHI mediates the relationship between generic job demands and (a) emotional exhaustion, (b) depersonalization.

Hypothesis 6: Time-based negative WHI mediates the relationship between GP-specific job demands and (a) emotional exhaustion and (b) depersonalization.

Hypothesis 7: Strain-based negative WHI mediates the relationship between generic job demands and (a) emotional exhaustion and (b) depersonalization.

Hypothesis 8: Strain-based negative WHI mediates the relationship between GP-specific job demands and (a) emotional exhaustion and (b) depersonalization.

The relationships as described in the above hypotheses are depicted in Figure 1.

\section{Method}

\section{Sample and procedure}

Data were collected among a sample of GPs registered in the Netherlands. At the time of data collection, 11,834 GPs were registered. Of this total number, a random sample of 900 GPs received an invitation letter in which they were asked to participate in a study on work characteristics, work-home conflict and burnout among GPs. The data were collected through an online questionnaire, which was distributed via SurveyMonkey from July to September 2017. After 6 weeks a reminder was sent. Immediately upon receipt of the completed survey, 


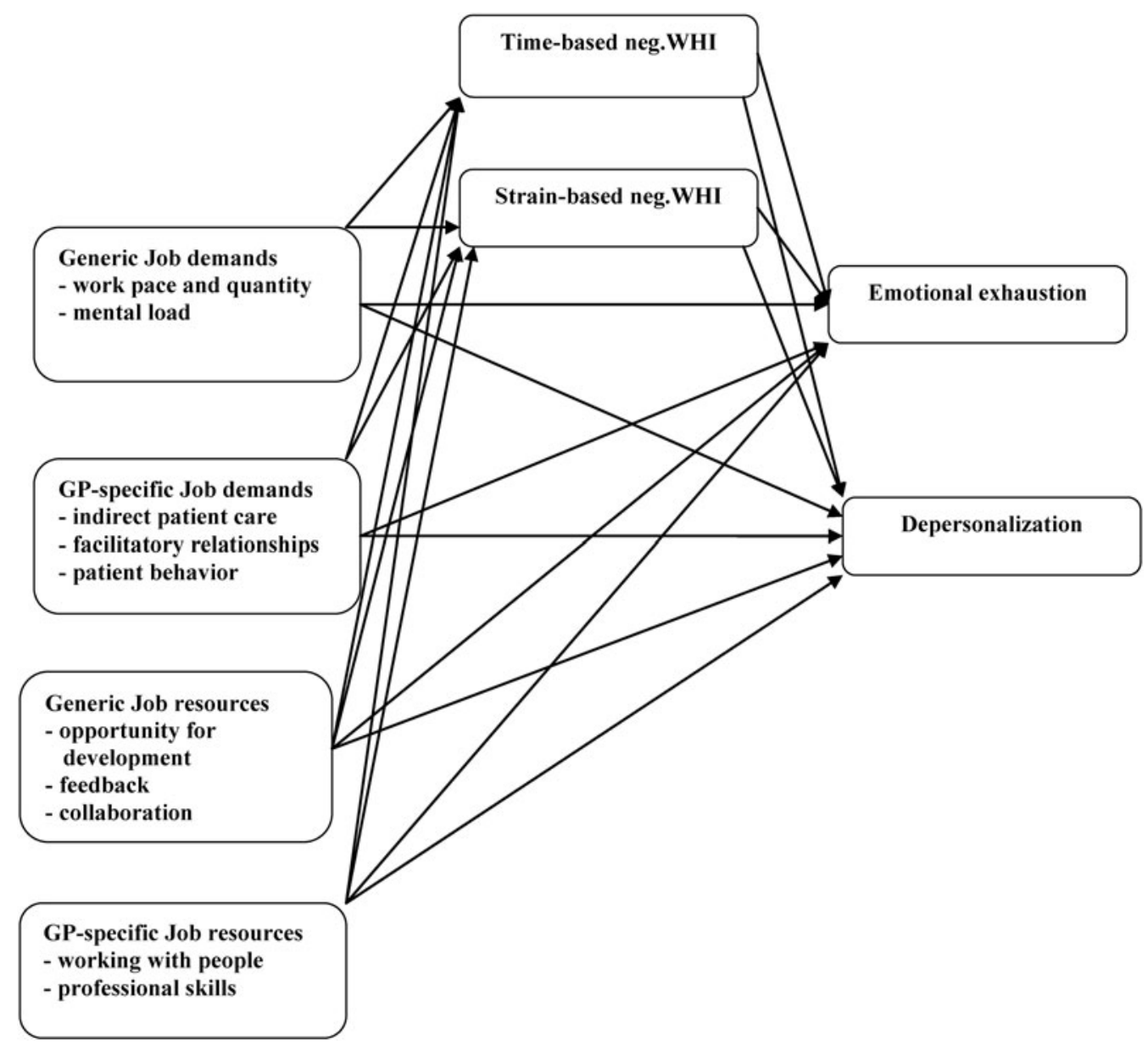

Fig. 1. Conceptual model.

Note: In Figure 1, the occupation-specific job demands and job resources that are examined in this study are indicated. These variables have not specifically been introduced in the theoretical framework, as the identification of these variables was part of the results of a pre-study in which interviews with GPs were conducted.

confidential data (name, address, email address) were separated and destroyed. The remaining data were anonymized and were stored on a USB stick in a safe.

One-hundred and seventy-eight GPs responded to the questionnaire. Of the 178 respondents, 14 respondents $(7,87 \%)$ did not fill in all the items of the study constructs, while 18 respondents $(10,11 \%)$ did not respond to all demographic questions. The impact of missing data on quantitative research can be serious, leading to biased estimates of parameters (Newman, 2014; Rubin, 1988; Schafer, 1997), loss of information, decreased statistical power, increased standard errors (Peng, Harwell, Liou, \& Ehman, 2006) and weakened generalizability of findings (Schafer \& Graham, 2002). Due to the relatively low level of missing data for the study constructs, the expectation-maximization (EM) algorithm for single imputation is considered appropriate for the present study (Dempster, Laird, \& Rubin, 1977; Malhotra, 1987).

Of the 178 respondents, 66 (37.07\%) were female, 94 (52.80\%) were male, while $18(10.11 \%)$ respondents did not indicate their gender. Participants were between 31 and 70 years old, with a mean age of 50.54 years $(S D=10,26)$. One-hundred forty-four respondents $(80.90 \%)$ lived together with a partner, nine (5.01\%) were single, while seven respondents $(3.94 \%)$ did not 
indicate their living situation. Thirty-nine (21.91\%) respondents practised in a solo practice, 46 $(25.84 \%)$ in a duo practice, $59(33.15 \%)$ in a group practice, while $16(8.99 \%)$ practised as a locum. Of those respondents that held a practice, they employed an average of 6.28 employees $(\mathrm{SD}=3.05)$, ranging from 1 to 10 employees. The average tenure with the practice was 15.96 years $(\mathrm{SD}=10.33)$ ranging from 1 to 37 years.

To determine how well the sample $(n=178)$ generalized to the population of GPs $(n=11834)$ we compared our sample's characteristics with regard to practice type, gender and age to that of the broader population (Van Der Velden, Kasteleijn, \& Kenens, 2017). The percentage of GPs that practised in a solo practice was not very different from the general population $(21.9 \%$ vs. 18\%). However, there were substantial differences between our sample and the general population with regard to practising in a duo practice $(25.88 \%$ vs. $40 \%)$ and group practice $(33.15 \%$ vs. $22 \%)$. In our sample, $20.8 \%$ of the respondents were below the age of 40 years which was not very different from the population (25\%). However, in our sample, the percentage of female respondents (37.1\%) was underrepresented compared to the percentage of females in the general GP population (51\%). All in all, the results show that the sample of GPs is similar to the population of GPs in some respects but also differs in other aspects.

\section{Measurement instruments}

For all measurement instruments except those assessing occupation-specific demands and resources, existing validated Dutch measurement instruments were used. For the measurement scales of occupation-specific demands and resources, items were self-constructed based on interviews with eight GPs.

\section{Occupation-specific job demands and resources}

Interviews were conducted with eight GPs to obtain a better understanding of the occupationspecific job demands and resources experienced by GPs in the Netherlands. The interviews inquired about aspects of the work and non-work domain that cost energy and those that provide energy. Interviews lasted from 33 to $48 \mathrm{~min}$ with an average of $40 \mathrm{~min}$. Three female and five male GPs with an average age of 52 years ranging from 32 to 66 years participated. On average, interviewees had worked as a GP for 21 years. The interviewees worked in different types of practices, four worked in a duo practice, two in group practice and two in a solo practice.

The interviews were analysed by means of template analysis (Crabtree \& Miller, 1999; King, 1998, 2012). Based on the analyses, themes with the highest number of quotes were assumed to represent what is important among GPs. While some GPs experienced out-of-hours services and management tasks as costing energy, others experienced them as providing energy. These two work characteristics were included in the questionnaire under occupation-specific job demands and resources. However, as a demand, they were preceded by the statement that it was an activity that consumed energy, as a resource, they were preceded by the statement that it was an activity that generated energy.

Occupation-specific job demands were measured by 13 items which were formulated based on the outcome of the interviews. Respondents were given the following instructions. Below are some aspects of the daily practice that generally cost energy. Please check how often a situation applies to you. Examples of aspects of daily practice included 'Dissatisfied patients', 'Maintaining external relations (physiotherapists, community nurses etc.)' and 'Insurers'. Respondents could answer on a 7-point Likert scale ranging from never to always.

A principal component analysis (PCA) was conducted to determine any underlying dimensions of the occupation-specific job demands. Factor extraction was based on parallel analysis (Horn, 1965). Parallel analysis was performed in Monte-Carlo PCA Parallel Analysis Software developed by Watkins (2000) based on 13 variables, 178 participants, and 1000 replications. Based on these parameters, a random matrix was generated. The unrotated eigenvalues were 
compared to the eigenvalues of those of the random matrix generated by the software. The number of factors to retain is based on the number of unrotated eigenvalues greater than those of the random matrix (Tolin, Brady, \& Hannan, 2008). The results showed that three unrotated eigenvalues were greater than those of the random matrix. Therefore, three factors were extracted. An oblique rotation method (Direct Oblimin) was used. The minimum cutoff value for factor loadings was set at .45. According to Hair, Black, Anderson, and Babin (2018), with a sample size of 150 , a factor loading of 45 is needed, while a sample size of 200 calls for factor loadings of at least .40 . As our sample fell in between 150 and 200, we adhered to the more conservative .45 criterion. Three items were removed based on cross-loadings and factor loadings lower than .45. Ten items were retained representing three factors. The first factor, 'Indirect patient care', explained 37.58 of the variance. The second factor, 'Facilitatory relationships', explained $19.38 \%$ of the variance. The third factor 'Patient behaviour', explained $13.26 \%$ of the variance. The results of the PCA are presented in Table 1 - panel A.

Occupation-specific job resources were measured by 10 items which were formulated based on the outcome of the interviews. Respondents were asked to consider aspects of daily practice that generally generate energy and indicate the frequency with which a situation applied to them. Example items include 'Having a good conversation with the patient', 'Make a correct diagnosis', and 'Relationship with patients (knowing)'. Respondents could answer on a 7-point Likert scale ranging from never to always.

A PCA was conducted to determine any underlying dimensions of occupation-specific job resources. Factor extraction was calculated by means of parallel analysis (Watkins, 2000) including 10 variables, 178 participants, and 1000 replications. The results indicated that two factors should be retained. An oblique rotation method (Direct Oblimin) was used. Items with a minimum factor loading of .45 were retained (Hair et al., 2018). Two items were removed, one based on cross-loadings, and one due to a factor loading below .45. Eight items representing two factors were retained. The first factor, 'Working with people', explained $44.67 \%$ of the variance. The second factor, 'Professional skills', explained $15.57 \%$ of the variance. The results of the factor analysis are presented in Table 1 - panel B.

\section{Generic job demands}

Work pace and quantity (WPQ) was measured with six items and mental pressure with four items from the Perception and Assessment of Labor questionnaire developed by Van Veldhoven, Prins, Van Der Laken, and Dijkstra (2015). Example items include 'Do you have to work extra hard to get something done?' (WPQ) and 'Does your work require that you always have to think thoroughly about it?' (mental pressure). The questions were answered on a 4-point Likert scale ranging from always to never.

\section{Generic job resources}

The three-item scales presented in Bakker (2014) were used to measure generic job resources. The items measuring opportunity for development and feedback were rated on a 4-point Likert scale, ranging from always to never. The items for collaboration were rated on a 5-point Likert scale, ranging from always to never. Example items include 'In my work, I can develop myself sufficiently' (opportunities for development), 'I receive sufficient information about the results of my work' (feedback), and 'If necessary can you ask your colleagues for help?' (collaboration).

\section{Negative WHI}

The Survey Work-Home Interaction-Nijmegen (SWING) developed by Geurts et al. (2005) was used to measure strain-based negative WHI (4 items) and time-based negative WHI (4 items). Items were measured on a 4-point Likert scale ranging from always to never. Example items include 'How often does it happen that you are irritable at home because your work is 
Table 1. Exploratory factor analyses occupation-specific demands and resources

\begin{tabular}{|c|c|c|c|}
\hline & $\begin{array}{l}\text { Indirect } \\
\text { patient care }\end{array}$ & $\begin{array}{l}\text { Facilitatory } \\
\text { relationships }\end{array}$ & $\begin{array}{l}\text { Patient } \\
\text { behaviour }\end{array}$ \\
\hline \multicolumn{4}{|c|}{ Panel A: Occupation-specific job demands } \\
\hline $\begin{array}{l}\text { Colleague GPs (regular consultation, locum in case of } \\
\text { illness, etc.) }\end{array}$ & .88 & & \\
\hline $\begin{array}{l}\text { Collaboration (colleague GPs, physiotherapists, } \\
\text { district nurses, etc.) }\end{array}$ & .86 & & \\
\hline Personnel & .82 & & \\
\hline $\begin{array}{l}\text { Maintaining external relationships (physiotherapists, } \\
\text { district nurses, etc.) }\end{array}$ & .80 & & \\
\hline $\begin{array}{l}\text { Administration (keeping patient records, inquiries, } \\
\text { etc.) }\end{array}$ & .66 & & \\
\hline $\begin{array}{l}\text { Information technology (anything that has to do with } \\
\text { computers, operating GP information system, } \\
\text { printers, paper, etc.) }\end{array}$ & .66 & & \\
\hline Insurers & & .89 & \\
\hline $\begin{array}{l}\text { Business relationships (inspection for public health, } \\
\text { suppliers, etc.) }\end{array}$ & & .84 & \\
\hline Dissatisfied patients & & & .90 \\
\hline Claiming patients & & & .84 \\
\hline \multirow[t]{2}{*}{ Explained variance } & $37.58 \%$ & $19.38 \%$ & $13.26 \%$ \\
\hline & Working with & & Professional skills \\
\hline \multicolumn{4}{|c|}{ Panel B: Occupation-specific resources } \\
\hline Relationship with patients (interaction) & .85 & & \\
\hline Direct patient care & .83 & & \\
\hline Relationship with patients (knowing) & .80 & & \\
\hline Professional autonomy & .73 & & \\
\hline Having a good conversation with the patient & .64 & & \\
\hline Specialization (minor surgery, medical officer) & & & .89 \\
\hline Providing education & & & .71 \\
\hline Sixth sense experience & & & .52 \\
\hline Explained variance & $44.67 \%$ & & $15.57 \%$ \\
\hline
\end{tabular}

$N=178$.

Principal component analysis (PCA) was used. Factor loadings below .30 were suppressed.

demanding' (strain-based) and 'How often do you have to cancel appointments with your partner/family/friends due to obligations at work?' (time-based).

\section{Burnout}

Emotional exhaustion and depersonalization were measured with respectively eight and four items from the UBOS-C scale (Schaufeli \& van Dierendonck, 2000). The items were measured on a 7-point Likert scale ranging from never to always. Example items include 'I feel mentally exhausted by my work' (emotional exhaustion) and 'I feel that I have become more indifferent to other people since I have this job' (depersonalization). 


\section{Measurement model}

We used confirmatory factor analysis (CFA) to assess the validity of the measurement instruments. Occupation-specific job demands and resources were not subjected to CFA because they were already subjected to PCA. Due to the relatively large number of items compared to the number of respondents, the suggested subject-to-item ratio of 10:1 for CFA (Tabachnick, Fidell, \& Ullman, 2007) was not achieved. Following Restubog, Hornsey, Bordia, and Esposo (2008), we assessed separate measurement models. Measurement model 1 comprised the generic job demands and resources with a subject-to-item ratio of 9.37:1. Measurement model 2 comprised strain- and time-based negative WHI, emotional exhaustion and depersonalization, with a subject-to-item ratio of 8.90:1.

To assess the fit of the measurement models, the following cutoff criteria were used. The comparative fit index (CFI) and the Tucker-Lewis index (TLI) had to be at least .90 (Hu \& Bentler, 1999; Tucker \& Lewis, 1973), the root mean square residual (RMR), the standardized root mean square residual (RMSR) and the root mean square error of approximation had to be smaller than .08 (Hu \& Bentler, 1999). Furthermore, factor loadings had to be at least .50 (Hair, Black, Babin, \& Anderson, 2010). In addition, the average variance extracted (AVE) of the measures had to be at least .50 (Malhotra \& Dash, 2011) and the AVE should be larger than the squared correlations with the other latent variables (Fornell \& Larcker, 1981). Composite reliability (CR) should be at least .70 (Malhotra \& Dash, 2011), while the heterotrait-monotrait ratio (HTMT) should be smaller than .90 (Henseler, Ringle, \& Sarstedt, 2015).

The results of the initial CFA of measurement model 1 showed an acceptable fit with the data $\left(\chi^{2} / \mathrm{df}=1.71, \mathrm{RMR}=.03\right.$, SRMR $\left..06, \mathrm{RMSEA}=.06, \mathrm{TLI}=.90, \mathrm{CFI}=.92\right)$. However, the AVEs of WPQ and feedback were below .50. To improve the convergent validity, the indicator with the lowest loading (.50) was removed from the model. After removal of the item, the model fit slightly improved $\left(\chi^{2} / \mathrm{df}=1.51, \mathrm{RMR}=.03, \mathrm{SRMR}=.06, \mathrm{RMSEA}=.05, \mathrm{TLI}=.93, \mathrm{CFI}=.94\right)$, however, the AVEs of WPQ and feedback did not meet the .50 cut-off criterion. As deleting more items may compromise face validity, we assessed whether the measures adhered to other validity criteria. For all measures, the CRs were well above the cutoff criterium of .70. In addition, Cronbach's alphas were above .70. Moreover, the AVEs were larger than the squared correlations with the other latent variables and the HTMT ratios were below .90. Therefore, despite the lower AVEs for WPQ (.45) and feedback (.47), these measurements adhered to the other discriminant validity criteria. We, therefore considered Model $1 \mathrm{~b}$ to adequately fit the data. Model $1 \mathrm{~b}$ was compared to two alternative models, namely Model 1c (2-factor model) and Model 1d (1-factor model). The results (see Table 2), show that these models had a worse fit than Model $1 \mathrm{~b}$.

Model 2 comprised strain-based and time-based negative WHI, emotional exhaustion and depersonalization. The results of the initial model (Model 2a) show that the model did not have an adequate fit with the data $\left(\chi^{2} / \mathrm{df}=2.21, \mathrm{RMR}=.07, \mathrm{SRMR}=.08, \mathrm{RMSEA}=.08\right.$, $\mathrm{TLI}=.88, \mathrm{CFI}=.90)$. One item from the depersonalization measure had a low factor loading $(.47)$ and was removed. The subsequent Model $2 \mathrm{~b}$ had a reasonable fit with the data $\left(\chi^{2} / \mathrm{df}=2.13\right.$, $\mathrm{RMR}=.06, \mathrm{SRMR}=.07, \mathrm{RMSEA}=.08, \mathrm{TLI}=.90, \mathrm{CFI}=.91)$. The internal consistency of the measures is adequate, as CRs and Cronbach's alphas are at least .70. The AVEs of two measures are just below the .50 cut-off criterion (strain-based negative WHI $=.45$, time-based negative WHI is .46 ). However, as the CRs and Cronbach's alphas are adequate and a model which combines strain-based and time-based negative WHI does not have better fit with the data (see Model $2 \mathrm{~d}$ in Table 2), these measurements are considered adequate. Regarding discriminant validity, one item from the emotional exhaustion scale was deleted as the HTMT ratio was above the threshold of .90 for this item. The subsequent Model $2 \mathrm{c}$ had a good fit $\left(\chi^{2} / \mathrm{df}=2.10\right.$, $\mathrm{RMR}=. .06, \mathrm{SRMR}=.07, \mathrm{RMSEA}=.08, \mathrm{TLI}=.90, \mathrm{CFI}=.92)$ and a reasonable discriminant validity according to the HTMT ratios. Model $2 \mathrm{c}$ was compared with two alternative models, namely model 2d (a 3-factor model which combines strain-based and time-based negative WHI) and model 2e (a 2-factor model which combines strain-based and time-based negative WHI and 
Table 2. Fit indices measurement models

\begin{tabular}{|c|c|c|c|c|c|c|c|c|}
\hline Model & $\chi^{2}$ & df & $\chi^{2} / \mathrm{df}$ & RMR & SRMR & RMSEA & TLI & $\mathrm{CFI}$ \\
\hline \multicolumn{9}{|c|}{ Panel A - Model 1 (generic job demands and generic job resources) } \\
\hline 1a (hypothesized-model) & 243.02 & 142 & 1.71 & .03 & .06 & .06 & .90 & .92 \\
\hline 1b (5-Factor model) & 189.2 & 125 & 1.51 & .03 & .06 & .05 & .93 & .94 \\
\hline 1c (2-Factor model) & 639.86 & 134 & 4.78 & .08 & .12 & .15 & .48 & .55 \\
\hline 1d (1-Factor model) & 890.82 & 135 & 6.60 & .09 & .16 & .18 & .23 & .32 \\
\hline 1e (CLF model) & 189.20 & 124 & 1.53 & .03 & .06 & .06 & .93 & .94 \\
\hline \multicolumn{9}{|c|}{ Panel B - Model 2 (strain and time-based negative WHI, emotional exhaustion and depersonalization) } \\
\hline 2a (hypothesized-model) & 361.79 & 164 & 2.21 & .07 & .08 & .08 & .88 & .90 \\
\hline 2b (4-factor model) & 311.45 & 146 & 2.13 & .06 & .07 & .08 & .90 & .91 \\
\hline 2c (4-factor model) & 271.17 & 120 & 2.10 & .06 & .07 & .08 & .90 & .92 \\
\hline 2d (3-factor model) & 328.06 & 132 & 2.49 & .06 & .08 & .09 & .87 & .89 \\
\hline 2e (2-factor model) & 395.67 & 134 & 2.95 & .07 & .08 & .11 & .83 & .85 \\
\hline $2 f$ (1-factor model) & 473.83 & 135 & 3.51 & .07 & .09 & .12 & .78 & .81 \\
\hline $2 \mathrm{~g}$ (CLF model) & 271.21 & 1.28 & 2.12 & .0 .06 & .07 & .08 & .90 & .92 \\
\hline
\end{tabular}

$N=178$.

combines emotional exhaustion and depersonalization). Both model $2 \mathrm{~d}$ and model $2 \mathrm{e}$ had a worse fit compared with model $2 \mathrm{c}$ (see Table 2).

\section{Common method variance (CMV)}

Common method bias or common method variance (CMV) is the bias that arises from the measurement method and not from the measurement model's constructs (Podsakoff, Mackenzie, Lee, \& Podsakoff, 2003). If present, it is suggested that CMV can be detrimental to the parameter estimates of the relationship between constructs (Mackenzie \& Podsakoff, 2012). In the present study, a single source, cross-sectional survey approach was used. Therefore, the presence of $\mathrm{CMV}$ in the current study is not unlikely, and it is essential to determine whether CMV is an issue.

Two methods were used to test for the presence of CMV in the present study. First, Harman's single factor test was conducted. A CFA approach was used for this. Second, common latent factor tests according to the method of Podsakoff et al. (2003) and the modification of Williams, Edwards, and Vandenberg (2003) was performed. In Table 2, the fit indices of the one-factor models used to perform Harman's single factor tests in CFA are presented. The fit indices of both models $1 \mathrm{~d}$ and $2 \mathrm{f}$ show a poor fit with the data. Hence, a single factor model is not an appropriate fit to represent the data. Next, the results of two CFAs in which a common latent factor was included were performed to test for the presence of CMV. To assess whether CMV is a problem, it is important to examine the factor loadings of the items on their hypothesized factor with and without the inclusion of a common latent factor. When the common latent factor is included, the items should still load significantly and in the expected direction on their hypothesized factor ) (Ng \& Feldman, 2013). In addition, the loadings should be above .50 on their theorized factor, while the loadings on the common latent factor should be either insignificant or when significant they should be lower than the loadings on the theorized factors (Brammer, He, \& Mellahi, 2015). The results of these analyses are reported in Table A in the Appendix. The results show that the presence of severe CMV is unlikely. That is, all items load significantly and in the expected 
direction on their theorized factor when the common latent factor was included. In addition, while a few items had loadings below .50 on their theorized factor when the common factor was included, overall the factor loadings on the theorized factors are above .50. Moreover, the loadings on the common latent factor are either not significant or when significant they are lower than on the theorized factor.

\section{Analysis strategy}

The hypotheses were tested in MEDIATE (Hayes, 2013). Although the PROCESS macro has been introduced after the MEDIATE macro, MEDIATE offers the opportunity to include multiple independent variables in the same mediation analysis, while PROCESS only allows one independent variable to be included in the analysis. Hypotheses 1 through 4 involve linear relationships between the independent variables (generic and occupation-specific job demands and resources) and dependent variables (emotional exhaustion and depersonalization) which are denoted by the total effects models in MEDIATE. To test the mediating hypotheses 5 through 8 , the path product approach is used (Alwin \& Hauser, 1975). Whereas tests of mediation differ considerably in type I error and statistical power, the recommended mediation test is the product of the coefficients method (Alwin \& Hauser, 1975). In order for mediation to occur, the total effect of the X to Y relationship must be significant. Second, the relationship between the independent variable (X) and the mediator $(\mathrm{M})$, also referred to as path $\mathrm{A}$, and the relationship between the mediator and the outcome variable $(\mathrm{Y})$ must be significant (path $\mathrm{B}$ ). Next, the product of the a-path and the b-path $(\mathrm{AB})$, which is also denoted as the indirect effect in MEDIATE, must be significant. If these conditions are met, there is evidence of mediation (Mathieu \& Taylor, 2006). If there is no significant total effect between $\mathrm{X}$ and $\mathrm{Y}$, but the other conditions are met, then there is evidence of an indirect effect (Mathieu \& Taylor, 2006). To test for the mediated or indirect effect's significance, non-parametric bootstrapping is performed with 5000 subsamples and $95 \%$ confidence intervals (Preacher \& Hayes, 2008).

\section{Results}

The means, standard deviations, correlations and scale reliabilities (Cronbach $\alpha$ ) among the study variables are presented in Table 3.

The results of the hypothesis tests are included in Tables 4 and 5. According to Hypothesis 1, there is a positive relationship between generic job demands and (a) emotional exhaustion and (b) depersonalization. The results provide partial support for Hypothesis la but not Hypothesis $1 \mathrm{~b}$. WPQ $(B=.91, p<.05)$ is significantly directly and positively related to emotional exhaustion. Mental pressure is not significantly related to emotional exhaustion $(B=-.01$, $p>.05)$. WPQ $(B=.24, p>.05)$ and mental pressure $(B=-.14, p>.05)$ are both not significantly related to depersonalization.

According to Hypothesis 2, there is a positive relationship between occupation-specific job demands and (a) emotional exhaustion and (b) depersonalization. The results provide partial support for both hypotheses. While indirect patient care $(B=.20, p<.05)$ and patient behaviour $(B=.16, p<.05)$ are significantly directly and positively related to emotional exhaustion, facilitatory relationships $(B=-.02, p>.05)$ is not. Indirect patient care and patient behaviour are significantly directly and positively related to depersonalization $(B=.19, p<.05$ and $B=.17, p<.05$, respectively), while facilitatory relationships $(B=-.07, p>.05)$ is not.

Additional hierarchical regression analyses were performed to examine to what extent occupation-specific job demands explained additional variance in emotional exhaustion beyond generic job demands (regression analyses were limited to emotional exhaustion since generic demands were not significantly related to depersonalization). The results are included in Table B in the Appendix. Generic job demands explained a significant proportion of the variance in the outcome variable emotional exhaustion: $R^{2}=.36(p<.001)$. In step 2 , the occupation- 
Table 3. Mean, standard deviation, Pearson's correlation and Cronbachs $\alpha$ (diagonally in boldface)

\begin{tabular}{|c|c|c|c|c|c|c|c|c|c|c|c|c|c|c|c|c|c|}
\hline & Mean & Std. deviation & $N$ & $\mathrm{EE}$ & DP & WPQ & MENT & IPC & FR & PB & OPPOR & FEEDB & COLLA & WWP & PS & STRAIN & TIME \\
\hline $\mathrm{EE}$ & 2.68 & 1.004 & 178 & .91 & & & & & & & & & & & & & \\
\hline DP & 2.07 & .832 & 178 & $.603^{\star \star}$ & .73 & & & & & & & & & & & & \\
\hline WPQ & 2.58 & .491 & 178 & $.596^{\star \star}$ & $.321^{\star \star}$ & .78 & & & & & & & & & & & \\
\hline MENT & 3.36 & .504 & 178 & $.212^{\star \star}$ & .087 & $.249^{\star \star}$ & .81 & & & & & & & & & & \\
\hline IPC & 3.46 & 1.052 & 178 & $.407^{\star \star}$ & $.381^{\star \star}$ & $.335^{\star \star}$ & $.156^{\star}$ & .87 & & & & & & & & & \\
\hline FR & 2.94 & 1.171 & 178 & .029 & -.055 & .054 & .017 & .067 & .75 & & & & & & & & \\
\hline PB & 3.36 & 1.019 & 178 & $.340^{\star \star}$ & $.289^{\star \star}$ & $.313^{\star \star}$ & $.322^{\star \star}$ & .091 & $.190^{\star}$ & .71 & & & & & & & \\
\hline OPPOR & 2.96 & .531 & 178 & $-.262^{\star \star}$ & $-.333^{\star \star}$ & $-.175^{\star}$ & -.116 & $-.286^{\star \star}$ & -.091 & $-.320^{\star \star}$ & .80 & & & & & & \\
\hline FEEDB & 2.53 & .541 & 178 & -.139 & -.120 & -.103 & -.118 & -.096 & .055 & -.108 & $.471^{\star \star}$ & .70 & & & & & \\
\hline COLLA & 3.70 & .845 & 178 & $-.201^{\star \star}$ & -.141 & -.090 & -.078 & -.010 & -.050 & -.113 & $.270^{\star \star}$ & $.219^{\star \star}$ & .84 & & & & \\
\hline WWP & 5.15 & .747 & 178 & $-.304^{\star \star}$ & $-.402^{\star \star}$ & $-.159^{\star}$ & -.102 & $-.239^{\star \star}$ & $.150^{\star}$ & -.069 & $.314^{\star \star}$ & $.199^{\star \star}$ & $.165^{\star}$ & .85 & & & \\
\hline PS & 4.32 & .988 & 178 & $-.177^{\star}$ & $-.175^{\star}$ & -.143 & $-.176^{\star}$ & $-.195^{\star \star}$ & $.167^{\star}$ & -.036 & $.255^{\star \star}$ & $.371^{\star \star}$ & $.237^{\star \star}$ & $.413^{\star \star}$ & .57 & & \\
\hline STRAIN & 2.13 & .477 & 178 & $.764^{\star \star}$ & $.384^{\star \star}$ & $.567^{\star \star}$ & $.305^{\star \star}$ & $.353^{\star \star}$ & .033 & $.355^{\star \star}$ & $-.275^{\star \star}$ & $-.152^{\star}$ & $-.181^{\star}$ & $-.151^{\star}$ & -.116 & .76 & \\
\hline TIME & 2.25 & .486 & 178 & $.491^{\star \star}$ & $.265^{\star \star}$ & $.597^{\star \star}$ & $.160^{\star}$ & $.310^{\star \star}$ & -.036 & $.269^{\star \star}$ & -.144 & -.072 & -.082 & -.084 & -.050 & $.625^{\star \star}$ & .76 \\
\hline
\end{tabular}

EE, emotional exhaustion; DP, depersonalization; WPQ, work pace and quantity; MENT, mental pressure; IPC, indirect patient care; FR, facilitatory relationships; PB, patient behaviour; OPPOR, opportunity; FEEDB,

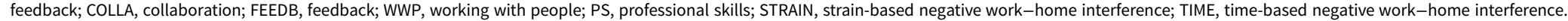
$N=178$. 
Table 4. Summary of mediation analysis mediation model dependent variable EE

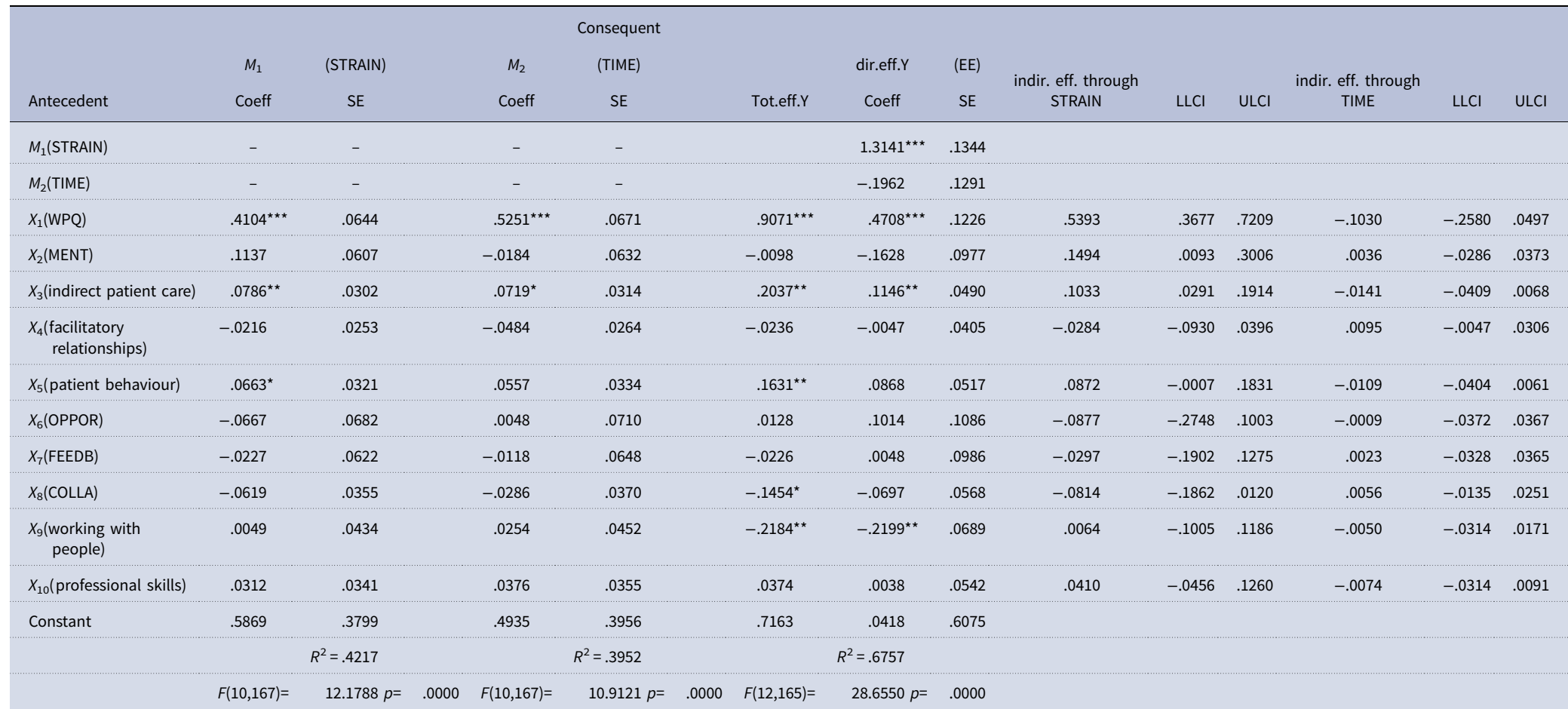

$N=178$.

${ }^{\star} p<.05{ }^{\star \star} p<.01{ }^{\star \star *} p<.001$. 


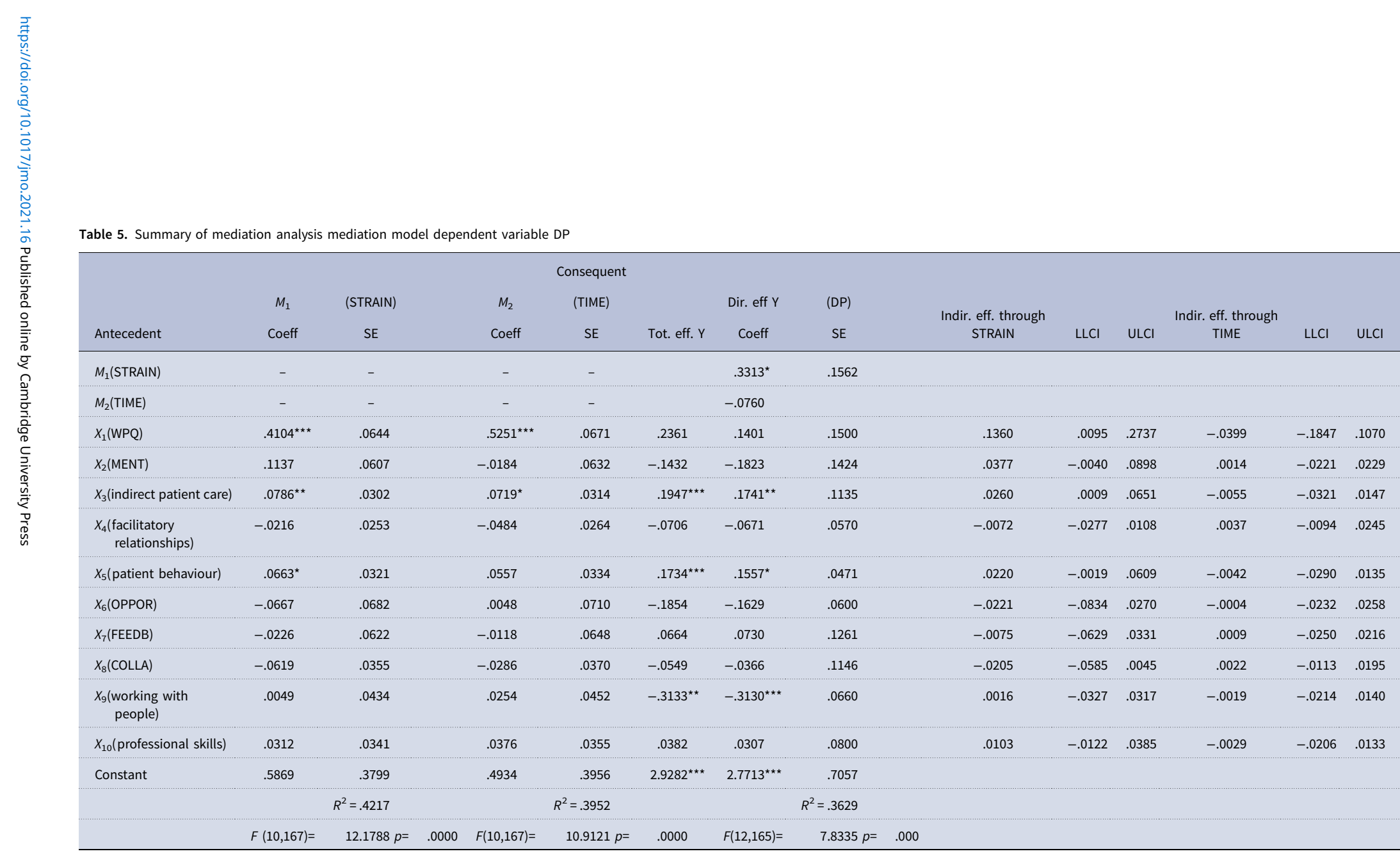

$N=178$.

${ }^{\star} p<.05{ }^{* \star} p<.01{ }^{\star \star \star} p<.001$ 
specific demands were added. Together the variables explained $43 \%$ of the variance in emotional exhaustion which is a significant increase of $7 \%\left(\Delta R^{2}=.07, p<.05\right)$.

According to Hypothesis 3, there is a negative relationship between generic job resources and (a) emotional exhaustion and (b) depersonalization. The results provide partial support for Hypothesis 3a since collaboration is negatively related to emotional exhaustion $(B=-.15, p<.05)$. Yet, the other two generic resources are not significantly related to emotional exhaustion (OPPOR $B=.01, p>.05$, FEEDB $B=-.02, p>.05$ ). Hypothesis $3 \mathrm{~b}$ is not supported (OPPOR $B=-.19, p>.05$, FEEDB $B=.07, p>.05$ and COLLA $B=-.04, p>.05$ ).

According to Hypothesis 4, there is a negative relationship between occupation-specific job resources and (a) emotional exhaustion and (b) depersonalization. The results provide partial support for Hypothesis $4 \mathrm{a}$ and partial support for Hypothesis $4 \mathrm{~b}$. While working with people is significantly negatively related to emotional exhaustion $(B=-.22, p<.05)$, professional skills is not $(B=.04, p>.05)$. Also, while working with people is significantly directly negatively related to depersonalization $(B=-.31, p<.05)$, professional skills $(B=.04, p>.05)$ is not.

According to Hypothesis 5, time-based negative WHI mediates the relationship between generic job demands and (a) emotional exhaustion and (b) depersonalization. The results provide no support for this hypothesis. The indirect effect of WPQ on emotional exhaustion through timebased negative WHI was not significant $(B=-.10,95 \%$ CI $[-.2580, .0497])$. In addition, the indirect effect of mental pressure on emotional exhaustion through time-based negative WHI was not significant $(B=.00,95 \% \mathrm{CI}[-.0286, .0373])$. Furthermore, the indirect effect of WPQ on depersonalization through time-based negative WHI was not significant $(B=-.04,95 \% \mathrm{CI}$ $[-.1847, .1070])$ and also the indirect effect of mental pressure on depersonalization through time-based negative WHI was not significant $(B=.0014,95 \%$ CI $[-. .221, .0229])$.

According to Hypothesis 6, time-based negative WHI mediates the relationship between occupation-specific job demands and (a) emotional exhaustion and (b) depersonalization. The results provide no support for this hypothesis. The indirect effects of indirect patient care, facilitatory relationships and patient behaviour through time-based negative WHI on emotional exhaustion were not significant $(B=-.01,95 \%$ CI $[-.0409, .0068] ; B=.01,95 \%$ CI $[-.0047$, $.0306] ; B=-.01,95 \% \mathrm{CI}[-.0404, .0061])$. Also, the indirect effects of indirect patient care, facilitatory relationships and patient behaviour through time-based negative WHI on depersonalization were not significant $(B=-.01,95 \%$ CI $[-.0321, .0147] ; B=.00,95 \% \mathrm{CI}[-.0094, .0245]$; $B=-.00,95 \% \mathrm{CI}[-.0290, .0135])$.

According to Hypothesis 7, strain-based negative WHI mediates the relationship between generic job demands and (a) emotional exhaustion and (b) depersonalization. The results provide partial support for this hypothesis. The indirect effect of WPQ through strain-based negative WHI on emotional exhaustion was statistically significant $(B=.54,95 \% \mathrm{CI}[.3677, .7209])$. While the indirect effect of mental pressure through strain-based negative WHI on emotional exhaustion was significant $(B=.15,95 \%$ CI $[.0093, .3006])$, the relationship between mental pressure and strain-based negative WHI was marginally significant $(B=.11, p<.10)$. Considering, path A was marginally significant, and the significance of path $\mathrm{A}$ is an important precondition for indirect effects (e.g., Mathieu \& Taylor, 2006; MacKinnon, Fairchild, \& Fritz, 2007), Hypothesis $7 \mathrm{a}$ is partly supported. The indirect effect of WPQ through strain-based negative WHI on depersonalization was significant $(B=.14,95 \%$ CI $[.0095, .2737])$. However, the indirect effect of mental pressure through strain-based negative WHI on depersonalization was not significant; $B=.04,95 \%$ CI $[-.0040, .0898])$. Thus, there is partial support for Hypothesis $7 \mathrm{~b}$. According to Hypothesis 8, strain-based negative WHI mediates the relationship between occupation-specific job demands and (a) emotional exhaustion and (b) depersonalization. The results provide partial support for Hypothesis $8 \mathrm{a}$ and partial support for Hypothesis $8 \mathrm{~b}$. The indirect effect of indirect patient care through strain-based negative WHI on emotional exhaustion was statistically significant $(B=.10,95 \%$ CI $[.0291, .194])$. However, the indirect effects of facilitatory relationships and patient behaviour through strain-based negative WHI on emotional 
exhaustion were not significant $(B=-.03,95 \% \mathrm{CI}[-.0930, .0396] ; B=.09,95 \% \mathrm{CI}[-.0007, .1831])$. The indirect effect of indirect patient care through strain-based negative WHI on depersonalization was significant $(B=.03,95 \%$ CI $[.0009, .0651])$. However, the indirect effects of facilitatory relationships and patient behaviour through strain-based negative WHI on depersonalization were not significant $(B=-.01,95 \%$ CI $[-.0277, .0108] ; B=.02,95 \%$ CI $[-.0019, .0609])$.

\section{Discussion}

Numerous studies have examined the causes of burnout (e.g., Azam, Khan, \& Alam, 2017; Johnson, Hall, Berzins, Baker, Melling, \& Thompson, 2018; Vladut \& Kállay, 2010). Moreover, multiple preventative and therapeutic interventions have been developed, including interventions aimed at strengthening resources and coping strategies as well as interventions aimed at reducing sources of stress and attempts to change the professional context (Ahola, Toppinen-Tanner, \& Seppänen, 2017; Panagioti et al., 2017). Still, burnout among GPs remains a significant problem (Rotenstein et al., 2018; West, Dyrbye, Erwin, \& Shanafelt, 2016). In this study, we therefore specifically examined the effects of both occupation-specific and generic job demands and resources to enhance further knowledge on the factors that are related to burnout among GPs. Besides, we explored the role of negative WHI (strain-based and time-based) to increase our understanding of how generic and occupation-specific demands and resources are related to burnout. In this way, an extended version of the JD-R model was considered, which can further enhance the development of new, or refined preventative and therapeutic interventions for burnout among GPs.

Although the importance of occupation-specific job demands and resources is emphasized in connection with the ecological validity of a study (Brough \& Biggs, 2015), only a few studies have examined the role of occupation-specific demands (e.g., Bakker et al., 2000; Van Ham, 2006) among GPs. Based on a survey study, Van Ham (2006) provided an overview of a GP's working environment. The results of our analysis of occupation-specific demands and resources show several overlaps with Van Ham (2006) study. Van Ham's (2006) study pointed to six aspects that are relevant to a GP's work environment, namely collaboration with and relationships with others, external work environment, satisfaction with the time available for work and private life, satisfaction with services, satisfaction with general aspects of the work and satisfaction with financial aspects. Several of these components are linked explicitly to the demands of GPs and can be linked to dimensions identified in our study. Those dimensions are indirect patient care, professional skills and facilitatory relationships. There are also differences; for example, the occupationspecific job demand 'patient behaviour' and the occupation-specific resource 'working with people' were not identified in Van Ham (2006). Hence, our study points to the importance of focusing on occupation-specific demands and resources related to relational aspects of the GP's work.

Bakker et al. (2000) investigated the relationship between one occupation-specific demand, having to deal with demanding patients, and burnout. In a longitudinal study, Bakker et al. (2000) demonstrated that perceiving patients to be demanding, ultimately leads to burnout among GPs. In our research, 'demanding patients' was also identified as an essential element of occupation-specific job demands that are negatively related to burnout. Although our study was cross-sectional, by examining the role of generic and occupation-specific demands simultaneously, our study adds to the existing body of knowledge, by showing the importance of this occupation-specific demand also when generic demands are examined. More specifically, while occupation-specific and generic job demands were both significantly related to emotional exhaustion, only occupation-specific job demands were significantly related to depersonalization.

Furthermore, we compared the results of our study with the results of Brough and Biggs (2015) and the results of De Croon et al. (2002). Both studies considered the role of occupation-specific job demands on outcomes. In both studies, additional variance in the outcome variables was explained by adding occupation-specific job demands to the model. In our study, the occupationspecific job demands explained additional variance in emotional exhaustion. Hence, we partially 
supported the central hypothesis of Brough and Biggs (2015) and De Croon et al. (2002) that by adding job-specific job demands to the research model, extra variance in the outcome variables (i.e., emotional exhaustion in our study) can be explained.

In this study, we examined the effects of strain-based and time-based negative WHI separately. Since not all independent variables were directly significantly related to the burnout components (WPQ was not significantly related to depersonalization), we refer to the general term intervening effects as opposed to the more specific mediated or indirect effects (see Mathieu and Taylor (2006) for a discussion of different types of intervening effects). As expected, strain-based negative WHI acted as an intervening variable in the relationships between both generic (WPQ) and occupation-specific demands (indirect patient care) and emotional exhaustion and depersonalization. However, contrary to our expectations, time-based negative WHI did not act as an intervening variable in the relationship between the job demands (generic and occupation-specific) and both components of burnout. Most existing research has examined the role of negative WHI as one unidimensional variable encompassing items assessing both time- and strain-based negative WHI. For example, Bakker et al. (2011) investigated the effects of several job demands and resources on negative WHI among a sample of medical residents and their partners. A combination of high job demands and low job resources was related to negative WHI. While the study was conducted among healthcare employees, since Bakker et al. (2011) did not distinguish between time- and strain-based negative WHI, previous research does not offer many insights for potential reasons for the result that time-based negative WHI does not play an indirect role in the relationship between demands and burnout in our study. There are several potential reasons for the unexpected finding. First, the results of our study point to the importance of the relational aspects of the GP's work. It is conceivable that relational aspects are not related to time but predominantly to stress. This proposition about the nature of job demands and resources could be further investigated in a future multigroup study in which the relationship between job demands of a different nature and strain- and time-based negative WHI are compared among employees from for example healthcare and financial organizations. Second, the nonsignificant findings may be a result of the combination of predictors included in the study. We draw from Hargis, Kotrba, Zhdanova, and Baltes (2011) study on antecedents of work-family conflict for a possible explanation. The results of this study suggest that combinations of variables can change a strong predictor of WHI (e.g., job stressors or negative affectivity) into a weak predictor of WHI. As an example, Hargis et al. (2011) mention family support. Previous research suggests that family support is significantly related to the different types of WHI (Ford, Heinen, \& Langkamer, 2007). In contrast, however, when this relationship was considered simultaneously with a significant number of antecedents, family support was found to explain only $0-5 \%$ of the predicted variance of the different types of WHI. Changes in predicted variance are known for some combinations of predictors, but not for many combinations. For future studies of WHI, this could mean that only a limited number of new predictors can be added to various known combinations from the literature.

Additionally, the results showed that only one generic job resource was significantly related to emotional exhaustion while none of the generic job resources had a significant relationship with depersonalization. One occupation-specific job resource, namely, working with people, was associated with both emotional exhaustion and depersonalization. These results show that it is essential to investigate occupation-specific job resources in the primary JD-R model, in addition to the generic job resources, because otherwise, the occupation-specific resources would have gone unnoticed. These results thus emphasize the added value of the occupation-specific extension of the JD-R model.

\section{Limitations and recommendations for future research}

The present study was cross-sectional, which means no conclusions about cause and effect relationships can be drawn. In the methods section, we demonstrated that although the sample 
represents the Dutch GP population in some respects, the sample does not represent the population of GPs well on a few other aspects. As a result, we need to be cautious with generalizing to the broader population. Addressing the representativeness of the present study, we would recommend replicating the present study among a more extensive, stratified sample (Groves, 2004; Rubin, 1987).

In our study, the indirect effect of strain-based negative WHI in the relationship between demands and emotional exhaustion was supported. However, an essential type of demand, i.e., home demands, was not considered in this study. A growing number of GPs is confronted with dual responsibilities, namely being a GP and at the same time, a caregiver for children (Michel et al., 2011). In addition to home demands, other types of resources, particularly the personal resources such as self-efficacy (Consiglio, Borgogni, Alessandri, \& Schaufeli, 2013; Xanthopoulou, Bakker, Demerouti, \& Schaufeli, 2007) and coping behaviour (Lazarus \& Folkman, 1984) should be included in future research.

\section{Practical implications}

The current study demonstrates the dominant role of work pressure, both in the work environment (WPQ, indirect patient care, patient behaviour) and in the interplay between the work environment and the home environment (strain-based negative WHI) in the emergence of burnout symptoms. This finding indicates a direction of intervention measures, namely the reduction of work pressure and a better balance between work and private life. From the perspective of occupation-specific demands, this could mean reducing the administrative burden. Because most GPs do not work in an employment contract but are independent entrepreneurs, intervention measures are not directly dependent on national politics, but GPs can take these measures independently. Another approach for intervention measures is the mediator framework which is a relatively new application in prevention and therapy research. In mediator frameworks, interventions are aimed at the manipulation of a mediating variable with an assumed causal relationship with the outcome variable. Regarding the current study, targeting a reduction of burnout, this would mean manipulating the mediator WHI, for example, by implementing childcare facilities.

\section{Conclusion}

Overall, our study indicated that the JD-R model should be expanded to include occupationspecific job demands and resources. Our study results show that burnout among GPs is mainly caused by WPQ, indirect patient care, such as administration and personnel, and patient behaviour, such as demanding patients, which are occupation-specific job demands. Hence, by focusing on both occupation-specific and generic demands, this study was able to shed light on the most relevant variables related to burnout among GPs. Moreover, the results showed that these demands specifically affected strain-based and not time-based negative WHI, which offers essential insights for interventions.

\section{Data availability statement}

The first author has made the data and accompanying data management and analysis procedure available online through Mendeley Database. Thisinformation can be accessed through the following link: Verhoef, N. C., De Ruiter, M., Blomme, R. J., \& Curfs, E. C. (2021). Burnout among Dutch generalpractitioners. Mendeley Data, V2, doi:10.17632/xz9wwsfbxk.2.

\section{References}

Abrahams, H., Houkes, I., Winants, Y. H. W. M., Twellaar, M., \& Verdonk, P. (2013). Gender en burnout bij nederlandse huisartsen. Tijdschrift voor Gezondheidswetenschappen, 91(4), 225-233. 
Ahola, K., Toppinen-Tanner, S., \& Seppänen, J. (2017). Interventions to alleviate burnout symptoms and to support return to work among employees with burnout: Systematic review and meta-analysis. Burnout Research, 4, 1-11.

Allen, T., Herst, D., Bruck, C., \& Sutton, M. (2000). Consequences associated with work-to-family conflict: A review and agenda for future research. Journal of Occupational Health Psychology, 5, 278-308.

Alwin, D. F., \& Hauser, R. M. (1975). The decomposition of effects in path analysis. American Sociological Review, 40(1), 3747.

Amstad, F. T., Meier, L. L., Fasel, U., Elfering, A., \& Semmer, N. K. (2011). A meta-analysis of work-family conflict and various outcomes with a special emphasis on cross-domain versus matching-domain relations. Journal of Occupational Health Psychology, 16(2), 151.

Azam, K., Khan, A., \& Alam, M. T. (2017). Causes and adverse impact of physician burnout: A systematic review. Journal of the College of Physicians and Surgeons--Pakistan: JCPSP, 27(8), 495-501.

Bacharach, S. B., Bamberger, P., \& Conley, S. (1991). Work-home conflict among nurses and engineers: Mediating the impact of role stress on burnout and satisfaction at work. Journal of Organizational Behavior, 12(1), 39-53.

Bakker, A. B. (2014). The job demands-resources questionnaire. Rotterdam: Erasmus University.

Bakker, A. B., \& Demerouti, E. (2007). The job demands-resources model: State of the art. In S.A.E. Sonnentag, P.L. Perrewe', \& D.C. Ganster (Eds), Journal of Managerial Psychology, 22(3), 309-328. https://doi.org/10.1108/02683940710733115

Bakker, A. B., Schaufeli, W. B., Sixma, H. J., Bosveld, W., \& Van Dierendonck, D. (2000). Patient demands, lack of reciprocity, and burnout: A five-year longitudinal study among general practitioners. Journal of Organizational Behavior, 21(4), 425-441.

Bakker, A. B., Ten Brummelhuis, L. L., Prins, J. T., \& Van Der Heijden, F. M. (2011). Applying the job demands-resources model to the work-home interface: A study among medical residents and their partners. Journal of Vocational Behavior, 79(1), 170-180.

Bakker, A. B., Verbeke, W., \& Demerouti, E. (2004). Using the job demands-resources model to predict burnout and performance. Human Resource Management, 43(1), 83-104.

Barling, J., Christie, A., \& Hoption, C. (2010). Handbook of industrial and organizational psychology. Washington: APA Books.

Barnett, R. C. (2005). Dual-earner couples: Good/bad for her and/or for him. In S. E. Murphy \& D. F. Halpern (Eds.), From work-family balance to work-family interaction: Changing the metaphor (pp. 151-171). Mahwah, NJ: Lawrence Erlbaum Associates Publishers.

Barron, B. A. (2019). Schonfeld, I.S. and Chang, C.:Occupational Health Psychology. Journal of Occupational Rehabilitation, 29(1), 239-239.

Bellavia, G. M., \& Frone, M. R. (2005). Work-family conflict. In J. Barling, E. K. Kelloway, \& M. R. Frone (Eds.), Handbook of work stress (pp. 185-221). Thousand Oaks, CA: Sage.

Boddy, C. R. (2011). Corporate psychopaths, bullying and unfair supervision in the workplace. Journal of Business Ethics, 100 (3), 367-379.

Brammer, S., He, H., \& Mellahi, K. (2015). Corporate social responsibility, employee organizational identification, and creative effort: The moderating impact of corporate ability. Group and Organization Management, 40(3), 323-352.

Brough, P., \& Biggs, A. (2015). Job demands $\times$ job control interaction effects: Do occupation-specific job demands increase their occurrence? Stress and Health, 31(2), 138-149.

Burns, R. A., Butterworth, P., \& Anstey, K. J. (2016). An examination of the long-term impact of job strain on mental health and wellbeing over a 12-year period. Social Psychiatry and Psychiatric Epidemiology, 51(5), 725-733.

Buunk, B., De Jonge, J., Ybema, J., \& De Wolff, C. (1998). Psychosocial aspects of occupational stress. Work psychology, handbook of work and organizational psychology (2nd edn). Hove: Psychology Press, Ltd.

Colligan, T. W., \& Higgins, E. M. (2006). Workplace stress: Etiology and consequences. Journal of Workplace Behavioral Health, 21(2), 89-97.

Consiglio, C., Borgogni, L., Alessandri, G., \& Schaufeli, W. B. (2013). Does self-efficacy matter for burnout and sickness absenteeism? The mediating role of demands and resources at the individual and team levels. Work and Stress, 27(1), 22-42.

Cordes, C. L., \& Dougherty, T. W. (1993). A review and an integration of research on job burnout. Academy of Management Review, 18(4), 621-656.

Crabtree, B. F., \& Miller, W. L. (1999). Doing qualitative research. Thousand Oaks: Sage Publications.

Crawford, E. R., Lepine, J. A., \& Rich, B. L. (2010). Linking job demands and resources to employee engagement and burnout: A theoretical extension and meta-analytic test. Journal of Applied Psychology, 95(5), 834-848.

Cropanzano, R., Rupp, D. E., \& Byrne, Z. S. (2003). The relationship of emotional exhaustion to work attitudes, job performance, and organizational citizenship behaviors. Journal of Applied Psychology, 88(1), 160.

Croxson, C. H., Ashdown, H. F., \& Hobbs, F. R. (2017). GPs' perceptions of workload in England: A qualitative interview study. The British Journal of General Practice, 67(655), e138-e147.

De Croon, E. M., Blonk, R. W., De Zwart, B. C., Frings-Dresen, M. H., \& Broersen, J. P. (2002). Job stress, fatigue, and job dissatisfaction in Dutch lorry drivers: Towards an occupation specific model of job demands and control. Occupational and Environmental Medicine, 59(6), 356-361. 
Demerouti, E., Bakker, A. B., Geurts, S. A., \& Taris, T. W. (2009). Daily recovery from work-related effort during non-work time. In Current perspectives on job-stress recovery (pp. 85-123). Bingley UK: Emerald Group Publishing Limited.

Demerouti, E., Bakker, A. B., Nachreiner, F., \& Schaufeli, W. B. (2001). The job demands-resources model of burnout. Journal of Applied Psychology, 86(3), 499-512.

Dempster, A. P., Laird, N. M., \& Rubin, D. B. (1977). Maximum likelihood from incomplete data via the EM algorithm. Journal of the Royal Statistical Society: Series B (Methodological), 39(1), 1-22.

Derks, D., \& Bakker, A. B. (2014). Smartphone use, work-home interference, and burnout: A diary study on the role of recovery. Applied Psychology, 63(3), 411-440.

Derks, D., Van Duin, D., Tims, M., \& Bakker, A. B. (2015). Smartphone use and work-home interference: The moderating role of social norms and employee work engagement. Journal of Occupational and Organizational Psychology, 88(1), 155-177.

Fernández, R., \& Wong, J. C. (2014). Divorce risk, wages and working wives: A quantitative life-cycle analysis of female labour force participation. The Economic Journal, 124(576), 319-358.

Fink, G. (2017). Selye's general adaptation syndrome: Stress-induced gastro-duodenal ulceration and inflammatory bowel disease. Stress (Amsterdam, Netherlands), 1, F5.

Folkman, S. (2013). Stress: Appraisal and coping. New York: Springer.

Ford, M. T., Heinen, B. A., \& Langkamer, K. L. (2007). Work and family satisfaction and conflict: A meta-analysis of crossdomain relations. Journal of Applied Psychology, 92(1), 57-80.

Fornell, C., \& Larcker, D. F. (1981). Evaluating structural equation models with unobservable variables and measurement error. Journal of Marketing Research, 18(1), 39-50.

Freudenberger, H. J., \& Richelson, G. (1980). Burnout: The high cost of high achievement. New York: Paperback - Bantam books.

Geurts, S. A., Kompier, M. A., Roxburgh, S., \& Houtman, I. L. (2003). Does work-home interference mediate the relationship between workload and well-being? Journal of Vocational Behavior, 63(3), 532-559.

Geurts, S., Rutte, C., \& Peeters, M. (1999). Antecedents and consequences of work-home interference among medical residents. Social Science \& Medicine, 48(9), 1135-1148.

Geurts, S. A. E., Taris, T. W., Kompier, M. A. J., Dikkers, J. S. E., Van Hooff, M. L. M., \& Kinnunen, U. M. (2005). Workhome interaction from a work psychological perspective: Development and validation of a new questionnaire, the SWING. Work \& Stress, 19(4), 319-339.

Green, D. E., Walkey, F. H., \& Taylor, A. J. (1991). The three-factor structure of the Maslach burnout inventory: A multicultural, multinational confirmatory study. Journal of Social Behavior and Personality, 6(3), 453.

Greenhaus, J. H., \& Beutell, N. J. (1985). Sources of conflict between work and family roles. Academy of Management Review, 10(1), 76-88.

Groves, R. M. (2004). Survey errors and survey costs (Vol. 536). Hoboken NJ: John Wiley \& Sons.

Guest, D. E. (2002). Perspectives on the study of work-life balance. Social Science Information, 41(2), 255-279.

Gyllensten, K., \& Palmer, S. (2005). The role of gender in workplace stress: A critical literature review. Health Education Journal, 64(3), 271-288.

Hackman, J. R., \& Oldham, G. R. (1975). Development of the job diagnostic survey. Journal of Applied Psychology, 60(2), 159170.

Hair, J. F., Black, W. C., Anderson, R. E., \& Babin, B. J. (2018). Multivariate Data Analysis (8th ed.). London: Cengage.

Hair, J. F., Black, W. C., Babin, B. J., \& Anderson, R. E. (2010). Multivariate data analysis: International version. New Jersey: Pearson.

Hargis, M. B., Kotrba, L. M., Zhdanova, L., \& Baltes, B. B. (2011). What's really important? Examining the relative importance of antecedents to work-family conflict. Journal of Managerial Issues, 386-408.

Hayes, A. (2013). Introduction to mediation, moderation, and conditional process analysis. New York, NY: Guilford. New York, NY: Guilford Press.

Henseler, J., Ringle, C. M., \& Sarstedt, M. (2015). A new criterion for assessing discriminant validity in variance-based structural equation modeling. Journal of the Academy of Marketing Science, 43(1), 115-135.

Hobfoll, S. E. (1989). Conservation of resources: A new attempt at conceptualizing stress. American Psychologist, $44(3), 513$.

Hobfoll, S. E. (2002). Social and psychological resources and adaptation. Review of General Psychology, 6(4), 307-324.

Hobfoll, S. E., \& Shirom, A. (1993). Stress and burnout in the workplace: Conservation of resources. Handbook of Organizational Behavior, 1, 41-61.

Hoel, H., Sparks, K., \& Cooper, C. L. (2001). The cost of violence/stress at work and the benefits of a violence/stress-free working environment. Geneva: International Labour Organization, $81 \mathrm{pp}$.

Horn, J. L. (1965). A rationale and test for the number of factors in factor analysis. Psychometrika, 30(2), 179-185.

Hu, L. T., \& Bentler, P. M. (1999). Cutoff criteria for fit indexes in covariance structure analysis: Conventional criteria versus new alternatives. Structural Equation Modeling: A Multidisciplinary Journal, 6(1), 1-55.

Iacobucci, G. (2014). GPS' workload climbs as government austerity agenda bites. British Medical Journal, 349 , g4300.

International Labour Organization. (2016). Workplace Stress: A Collective Challenge. 
Janssen, P. P. M., Peeters, M. C. W., De Jonge, J., Houkes, I., \& Tummers, G. E. R. (2004). Specific relationships between job demands, job resources and psychological outcomes and the mediating role of negative work-home interference. Journal of Vocational Behavior, 65(3), 411-429.

Johnson, J., Hall, L. H., Berzins, K., Baker, J., Melling, K., \& Thompson, C. (2018). Mental healthcare staff well-being and burnout: A narrative review of trends, causes, implications, and recommendations for future interventions. International Journal of Mental Health Nursing, 27(1), 20-32.

Kahn, R. L., \& Byosiere, P. (1992). Stress in organizations. In M. D. Dunnette \& L. M. Hough (Eds.), Handbook of industrial and organizational psychology (pp. 571-650). Palo Alto, CA: Consulting Psychologists Press.

Katz, D., \& Kahn, R. L. (1978). The social psychology of organizations (Vol. 2). New York: Wiley.

Keenan, A., \& Newton, T. (1985). Stressful events, stressors and psychological strains in young professional engineers. Journal of Organizational Behavior, 6(2), 151-156.

King, N. (1998). Template analysis. In G. Symon \& C. Cassell (Eds.), Qualitative methods and analysis in organizational research: A practical guide (pp. 118-134). London: Sage.

King, N. (2012). Doing Template analysis. In G. Symon \& C. Cassell (Eds.), Qualitative organizational research: Core methods and current challenges (Vol. 426, pp. 426-450). London: Sage.

Kinnunen, U., \& Mauno, S. (1998). Antecedents and outcomes of work-family conflict among employed women and men in Finland. Human Relations, 51(2), 157-177.

Koekemoer, F. E., \& Mostert, K. (2006). Job characteristics, burnout and negative work-home interference in a nursing environment. SA Journal of Industrial Psychology, 32(3), 87-97.

Kopelman, R. E., Greenhaus, J. H., \& Connolly, T. F. (1983). A model of work, family, and interrole conflict: A construct validation study. Organizational Behavior and Human Performance, 32(2), 198-215.

Korpi, T., \& Tåhlin, M. (2011). Changing work-life inequality in Sweden: Globalization and other causes. In H. P. Blossfeld, S. Buchholz, D. Hofäcker, \& K. Kolb (Eds.), Globalized labour markets and social inequality in Europe (pp. 177-208). Basingstoke, UK: Palgrave MacMillan.

Kossek, E. E., Baltes, B. B., \& Matthews, R. A. (2011). How work-family research can finally have an impact in organizations. Industrial and Organizational Psychology, 4(3), 352-369.

Kristensen, T. S., Borritz, M., Villadsen, E., \& Christensen, K. B. (2005). The Copenhagen burnout inventory: A new tool for the assessment of burnout. Work and Stress, 19, 192-207.

Kushnir, T., Greenberg, D., Madjar, N., Hadari, I., Yermiahu, Y., \& Bachner, Y. G. (2013). Is burnout associated with referral rates among primary care physicians in community clinics? Family Practice, 31(1), 44-50.

Lazarus, R. S., \& Folkman, S. (1984). Appraisal, stress, and coping. Berlin, Heidelberg, New York: Springer.

Lee, R. T., \& Ashforth, B. E. (1996). A meta-analytic examination of the correlates of the three dimensions of job burnout. Journal of Applied Psychology, 81, 123-133.

Lingard, H., \& Francis, V. (2005). Does work-family conflict mediate the relationship between job schedule demands and burnout in male construction professionals and managers? Construction Management and Economics, 23(7), $733-745$.

Linzer, M., Visser, M. R., Oort, F. J., Smets, E. M., Mcmurray, J. E., \& De Haes, H. C. (2001). Predicting and preventing physician burnout: Results from the United States and the Netherlands. The American Journal of Medicine, 111(2), 170-175.

Lu, C.-Q., Wang, B., Siu, O.-L., Lu, L., \& Du, D.-Y. (2015). Work-home interference and work values in greater China. Journal of Managerial Psychology, 30(7), 801-814.

Mackenzie, S. B., \& Podsakoff, P. M. (2012). Common method bias in marketing: Causes, mechanisms, and procedural remedies. Journal of Retailing, 88(4), 542-555.

MacKinnon, D. P., Fairchild, A. J., \& Fritz, M. S. (2007). Mediation Analysis. Annual Review of Psychology, 58, 593-614.

Malhotra, N. K. (1987). Analyzing marketing research data with incomplete information on the dependent variable. Journal of Marketing Research, 24(1), 74-84.

Malhotra, N., \& Dash, S. (2011). Marketing research: An applied orientation (pp. 552-582). Upper Saddle River, NJ: Prentice-Hall.

Maslach, C. (1978). Job burnout: How people cope. Public Welfare, 36(2), 56-58.

Maslach, C., \& Leiter, M. P. (2016a). Burnout. In G. Fink (Ed.), Stress: Concepts, cognition, emotion, and behavior (pp. 351357). London: Elsevier.

Maslach, C., \& Leiter, M. P. (2016b). Understanding the burnout experience: Recent research and its implications for psychiatry. World Psychiatry, 15(2), 103-111.

Maslach, C., Schaufeli, W. B., \& Leiter, M. P. (2001). Job burnout. Annual Review of Psychology, 52, 397-422. doi: https://doi. org/10.1146/annurev.psych.52.1.397.

Mathieu, J. E., \& Taylor, S. R. (2006). Clarifying conditions and decision points for mediational type inferences in organizational behavior. Journal of Organizational Behavior: The International Journal of Industrial, Occupational and Organizational Psychology and Behavior, 27(8), 1031-1056.

Mcnall, L. A., Nicklin, J. M., \& Masuda, A. D. (2010). A meta-analytic review of the consequences associated with workfamily enrichment. Journal of Business and Psychology, 25(3), 381-396. 
Meijman, T., \& Mulder, G. (1998). Psychological aspects of workload. In P. J. D. Drenth \& H. Thierry (Eds.), Handbook of work and organizational psychology (pp. 5-34). Hove: Psychology Press.

Melamed, S., Shirom, A., Toker, S., Berliner, S., \& Shapira, I. (2006). Burnout and risk of cardiovascular disease: Evidence, possible causal paths, and promising research directions. Psychological Bulletin, 132(3), 327-353.

Michel, J. S., Kotrba, L. M., Mitchelson, J. K., Clark, M. A., \& Baltes, B. B. (2011). Antecedents of work-family conflict: A meta-analytic review. Journal of Organizational Behavior, 32(5), 689-725.

Montgomery, A., Panagopolou, E., \& Benos, A. (2005). Work-family interference as a mediator between job demands and job burnout among Greek doctors. Psychology \& Health, 20, 177-178.

Montgomery, A. J., Panagopolou, E., \& Benos, A. (2006). Work-family interference as a mediator between job demands and job burnout among doctors. Stress and Health, 22(3), 203-212.

Montgomery, A., Spânu, F., Băban, A., \& Panagopoulou, E. (2015). Job demands, burnout, and engagement among nurses: A multi-level analysis of ORCAB data investigating the moderating effect of teamwork. Burnout Research, 2(2-3), 71-79.

Naghieh, A., Montgomery, P., Bonell, C. P., Thompson, M., \& Aber, J. L. (2015). Organisational interventions for improving wellbeing and reducing work-related stress in teachers. Cochrane Database of Systematic Reviews, 4.

Newman, D. A. (2014). Missing data: Five practical guidelines. Organizational Research Methods, 17(4), $372-411$.

Ng, T. W. H., \& Feldman, D. C. (2013). Age and innovation-related behavior: The joint moderating effects of supervisor undermining and proactive personality. Journal of Organizational Behavior, 34(5), 583-606.

Panagioti, M., Panagopoulou, E., Bower, P., Lewith, G., Kontopantelis, E., Chew-Graham, C., ... Esmail, A. (2017). Controlled interventions to reduce burnout in physicians: A systematic review and meta-analysis. JAMA Internal Medicine, 177(2), 195-205.

Paoli, P., \& Merllié, D. (2005). Ten years of working conditions in the European Union (Summary). Report summary no. ef00128.

Parasuraman, S., Purohit, Y. S., Godshalk, V. M., \& Beutell, N. J. (1996). Work and family variables, entrepreneurial career success, and psychological well-being. Journal of Vocational Behavior, 48(3), 275-300.

Peng, C.-Y. J., Harwell, M., Liou, S.-M., \& Ehman, L. H. (2006). Advances in missing data methods and implications for educational research. Real Data Analysis, 3178, 31-78.

Podsakoff, P. M., Mackenzie, S. B., Lee, J.-Y., \& Podsakoff, N. P. (2003). Common method biases in behavioral research: A critical review of the literature and recommended remedies. Journal of Applied Psychology, 88(5), 879.

Preacher, K. J., \& Hayes, A. F. (2008). Asymptotic and resampling strategies for assessing and comparing indirect effects in multiple mediator models. Behavior Research Methods, 40(3), 879-891.

Rabidoux, S., \& Rottmann, A. (2017). Escaping burnout through collaboration: Co-teaching in a right-to-work state. Liberal Education, 103(1), n1.

Restubog, S. L. D., Hornsey, M. J., Bordia, P., \& Esposo, S. R. (2008). Effects of psychological contract breach on organizational citizenship behaviour: Insights from the group value model. Journal of Management Studies, 45(8), 1377-1400.

Rotenstein, L. S., Torre, M., Ramos, M. A., Rosales, R. C., Guille, C., Sen, S., \& Mata, D. A. (2018). Prevalence of burnout among physicians: A systematic review. JAMA, 320(11), 1131-1150. https://doi.org/10.1001/jama.2018.12777

Rubin, D. B. (1987). Multiple imputation for survey nonresponse. New York: Wiley.

Rubin, D. B. (1988). An overview of multiple imputation. Proceedings of the survey research methods section of the American Statistical Association.

Schafer, J. L. (1997). Analysis of incomplete multivariate data. New York, NY: Chapman \& Hall/CRC.

Schafer, J. L., \& Graham, J. W. (2002). Missing data: Our view of the state of the art. Psychological Methods, $7(2), 147$.

Schaufeli, W. B., \& Taris, T. W. (2005). The conceptualization and measurement of burnout: Common ground and worlds apart the views expressed in Work \& Stress Commentaries are those of the author(s), and do not necessarily represent those of any other person or organization, or of the journal. Work \& Stress, 19(3), 256-262.

Schaufeli, W. B., \& Taris, T. W. (2014). A critical review of the job demands-resources model: Implications for improving work and health. In G. F. Bauer \& O. Hämmig (Eds.), Bridging occupational, organizational and public health (pp. 43-68). Dordrecht, NL: Springer.

Schaufeli, W. B., \& van Dierendonck, D. (2000). UBOS Utrechtse Burnout schaal: Handleiding. Lisse: Swets Test publishers.

Selye, H. (1936). A syndrome produced by diverse nocuous agents. Nature, 138(3479), 32-32.

Selye, H. (1950). Stress and the general adaptation syndrome. British Medical Journal, 1(4667), 1383.

Shirom, A. (2003). Job-related burnout: A review. In C. Quick \& L. E. Tetrick (Eds.), Handbook of occupational health psychology (pp. 245-264). Washington, DC: American Psychological Association.

Shirom, A., Toker, S., Shapira, I., Berliner, S., \& Melamed, S. (2005). The association between burnout, depression, anxiety, and inflammation biomarkers: C-reactive protein and fibrinogen in men and women. Journal of Occupational Health Psychology, 10(4), 344-362.

Singh, A. P., \& Kumar, A. (2011). Work-life balance, health, job involvement and conflict management as a function of level, tenure and marital status. Indian Journal of Community Psychology, 7(1), 173-189.

Staines, G. L. (1980). Spillover versus compensation: A review of the literature on the relationship between work and nonwork. Human Relations, 33(2), 111-129. 
Sundin, L., Hochwälder, J., \& Lisspers, J. (2011). A longitudinal examination of generic and occupational specific job demands, and work-related social support associated with burnout among nurses in Sweden. Work, 38(4), 389-400.

Swensen, S., Kabcenell, A., \& Shanafelt, T. (2016). Physician-organization collaboration reduces physician burnout and promotes engagement: The Mayo Clinic experience. Journal of Healthcare Management, 61(2), 105-127.

Tabachnick, B. G., Fidell, L. S., \& Ullman, J. B. (2007). Using multivariate statistics (Vol. 5). Boston, MA: Pearson.

Taris, T. W., Schreurs, P. J. G., \& Van Iersel-Van Silfhout, I. J. (2001). Job stress, job strain, and psychological withdrawal among Dutch university staff: Towards a dual process model for the effects of occupational stress. Work \& Stress, 15 (4), 283-296.

Thijs, P., Te Grotenhuis, M., Scheepers, P., \& Van Den Brink, M. (2019). The rise in support for gender egalitarianism in the Netherlands, 1979-2006: The roles of educational expansion, secularization, and female labor force participation. Sex Roles, 81(9), 1-16.

Tolin, D. F., Brady, R. E., \& Hannan, S. (2008). Obsessional beliefs and symptoms of obsessive-compulsive disorder in a clinical sample. Journal of Psychopathology and Behavioral Assessment, 30(1), 31-42.

Torppa, M., Kuikka, L., Nevalainen, M., \& Pitkälä, K. (2015). Emotionally exhausting factors in general practitioners' work. Scandinavian Journal of Primary Health Care, 33(3), 178-183.

Tucker, L. R., \& Lewis, C. (1973). A reliability coefficient for maximum likelihood factor analysis. Psychometrika, 38(1), 1-10.

Van Den Berg, M. J., De Bakker, D. H., Spreeuwenberg, P., Westert, G. P., Braspenning, J. C., Van Der Zee, J., \& Groenewegen, P. P. (2009). Labour intensity of guidelines may have a greater effect on adherence than GPs' workload. BMC Family Practice, 10(1), 74.

Van Der Velden, L., \& Batenburg, R. (2017). Aantal huisartsen en aantal FTE van huisartsen vanaf 2007 tot en met 2016 : werken er nu meer of minder huisartsen dan 10 jaar geleden en werken zij nu meer of minder FTE?. Utrecht, NL: Nivel.

Van Der Velden, L. F. J., Kasteleijn, A., \& Kenens, R. J.. (2017). Cijfers uit de registratie van huisartsen : peiling 2016.. Utrecht, NL: Nivel.

Van Dierendonck, D., Schaufeli, W. B., \& Sixma, H. J. (1994). Burnout among general practitioners: A perspective from equity theory. Journal of Social and Clinical Psychology, 13(1), 86-100.

Van Emmerik, I., Bakker, A., \& Euwema, M. (2004). What happens after the assessment center? Employees reactions to unfavorable performance feedback. The Journal of Management Development, 27(5), 513-527.

Van Ham, I. (2006). De arbeidssatisfactie van de Nederlandse huisarts. Groningen, NL: University Library.

Van Ruysseveldt, J., Verboon, P., \& Smulders, P. (2011). Job resources and emotional exhaustion: The mediating role of learning opportunities. Work \& Stress, 25(3), 205-223.

Van Steenbergen, E. F., Ellemers, N., \& Mooijaart, A. (2007). How work and family can facilitate each other: Distinct types of work-family facilitation and outcomes for women and men. Journal of Occupational Health Psychology, 12(3), 279.

Van Veldhoven, M. (2008). European perspectives on research, education and practice. In J. Houmont \& S. Leka (Eds.), Occupational health psychology (pp. 1-25). Nottingham, UK: Nottingham University Press.

Van Veldhoven, M., Prins, J., Van Der Laken, P., \& Dijkstra, L. (2015). QEEW2. 0: 42 short scales for survey research on work, well-being and performance (pp. 1-89). Amsterdam, NL: SKB.

Vladut, C. I., \& Kállay, É. (2010). Work stress, personal life, and burnout. Causes, consequences, possible remedies: A theoretical review. Cognition, Brain, Behavior, 14(3), 261.

Watkins, M. W. (2000). Monte Carlo PCA for parallel analysis [computer software] (pp. 432-442). State College, PA: Ed \& Psych Associates.

West, C. P., Dyrbye, L. N., Erwin, P. J., \& Shanafelt, T. D. (2016). Interventions to prevent and reduce physician burnout: A systematic review and meta-analysis. The Lancet, 388(10057), 2272-2281.

West, C. P., Dyrbye, L. N., \& Shanafelt, T. D. (2018). Physician burnout: Contributors, consequences and solutions. Journal of Internal Medicine, 283(6), 516-529.

Williams, L. J., Edwards, J. R., \& Vandenberg, R. J. (2003). Recent advances in causal modeling methods for organizational and management research. Journal of Management, 29(6), 903-936.

Xanthopoulou, D., Bakker, A. B., Demerouti, E., \& Schaufeli, W. B. (2007). The role of personal resources in the job demands-resources model. International Journal of Stress Management, 14(2), 121.

Zantinge, E. M., Verhaak, P. F., \& Bensing, J. M. (2005). The workload of GPs: Patients with psychological and somatic problems compared. Family Practice, 22(3), 293-297.

Nicolaas Cornelis Verhoef has been a GP for a respectable period and has gained much experience with colleagues and patients with burnout. His PhD research at the Open University of the Netherlands focuses on the causes of burnout among general practitioners, in particular on the interface between work and private life.

Melanie de Ruiter is an Associate Professor at the Center for Strategy, Organization and Leadership at Nyenrode Business Universiteit, the Netherlands. Her research focuses on psychological contracts, leadership, proactive behaviour, well-being and organisational change management. Melanie teaches courses on organisational behaviour, change management and research methods and data analysis. Her research has been published in, among others, The International Journal of 
Human Resource Management, Frontiers in Psychology and The Journal of Applied Behavioral Science. She currently serves/ has served on the editorial review board of the Journal of Applied Behavioral Science and the Journal of Managerial Psychology.

Robert Jan Blomme is Associate Dean of Degree Programs and a Full Professor of Organisational Behavior at the Center for Strategy, Organization and Leadership at Nyenrode Business Universiteit, the Netherlands. His primary research concerns psychological, sociological, humanistic and institutional aspects of organisational behaviour and organisational development. He uses different methodologies and methods in his research, varying from quantitative multivariate, SEM and multi-level approaches to qualitative interpretative methods, including grounded theory and analytical induction.

Emile Chris Curfs is a professor of Corporate Social Responsibility by Health Insurers at the Open University of the Netherlands. He is an employee at health insurance company VGZ, member of the Care Academy Program Council, member of the Pergamijn Supervisory board, chairman of the Quality and Safety Committee of Pergamijn and scientific director of the Academic Research Workplace Health Insurers. 


\section{Appendix}

Table A. Common method variance analysis

\begin{tabular}{|c|c|c|c|}
\hline Construct & Indicator & (standardized) Loading to proposed latent variable & (standardized) Loading to CMLV \\
\hline \multicolumn{4}{|c|}{ Panel A-Model 1 (generic job demands and generic job resources) } \\
\hline Work pace and quantity & q0001 & $.691^{\star \star \star}$ & $-.067(\mathrm{~ns})$ \\
\hline \multirow[t]{4}{*}{ (WPQ) } & q0002 & $.902^{\star \star \star}$ & $-.023(\mathrm{~ns})$ \\
\hline & q0003 & $.638^{\star \star \star}$ & $-.156(\mathrm{~ns})$ \\
\hline & q0004 & $.479^{\star \star \star}$ & $-.175(\mathrm{~ns})$ \\
\hline & q0006 & $.507^{\star \star \star}$ & $-.373^{\star \star \star}$ \\
\hline \multirow[t]{4}{*}{ Mental load (MENT) } & q0007 & $.603^{\star \star \star}$ & $-.116(\mathrm{~ns})$ \\
\hline & q0008 & $.717^{\star \star \star}$ & $.100(n s)$ \\
\hline & q0009 & $.828^{\star \star \star}$ & $.128(\mathrm{~ns})$ \\
\hline & q0010 & $.777^{\star \star \star}$ & $-.063(\mathrm{~ns})$ \\
\hline Opportunity for & q0014 & $.827^{\star \star \star}$ & $-.028(\mathrm{~ns})$ \\
\hline \multirow[t]{2}{*}{ development (OPPOR) } & q0015 & $.764^{\star \star \star}$ & $.575^{\star \star \star}$ \\
\hline & q0016 & $.590^{\star \star \star}$ & $.332^{\star \star \star}$ \\
\hline \multirow[t]{3}{*}{ Feedback (FEEDB) } & q0017 & $.603^{\star \star \star}$ & $.011(\mathrm{~ns})$ \\
\hline & q0018 & $.870^{\star \star \star}$ & $-.054(\mathrm{~ns})$ \\
\hline & q0019 & $.666^{\star \star \star}$ & .209 (ns) \\
\hline \multirow[t]{3}{*}{ Collaboration (COLLA) } & q0020 & $.821^{\star \star \star}$ & $.138(n s)$ \\
\hline & q0021 & $.867^{\star \star \star}$ & $-.005(\mathrm{~ns})$ \\
\hline & q0022 & $.688^{\star \star \star}$ & $.096(\mathrm{~ns})$ \\
\hline Average & & .708 & .029 \\
\hline \multicolumn{4}{|c|}{ Panel B-Model 2 (strain-based and time-based negative WHI, emotional exhaustion and depersonalization) } \\
\hline \multirow[t]{3}{*}{ Strain-based negative WHI (STRAIN) } & q0038 & $.704^{\star \star \star}$ & $.296^{\star}$ \\
\hline & q0032 & $.863^{\star \star \star}$ & $-.231(\mathrm{~ns})$ \\
\hline & q0041 & $.580^{\star \star \star}$ & $.483^{\star \star \star}$ \\
\hline
\end{tabular}




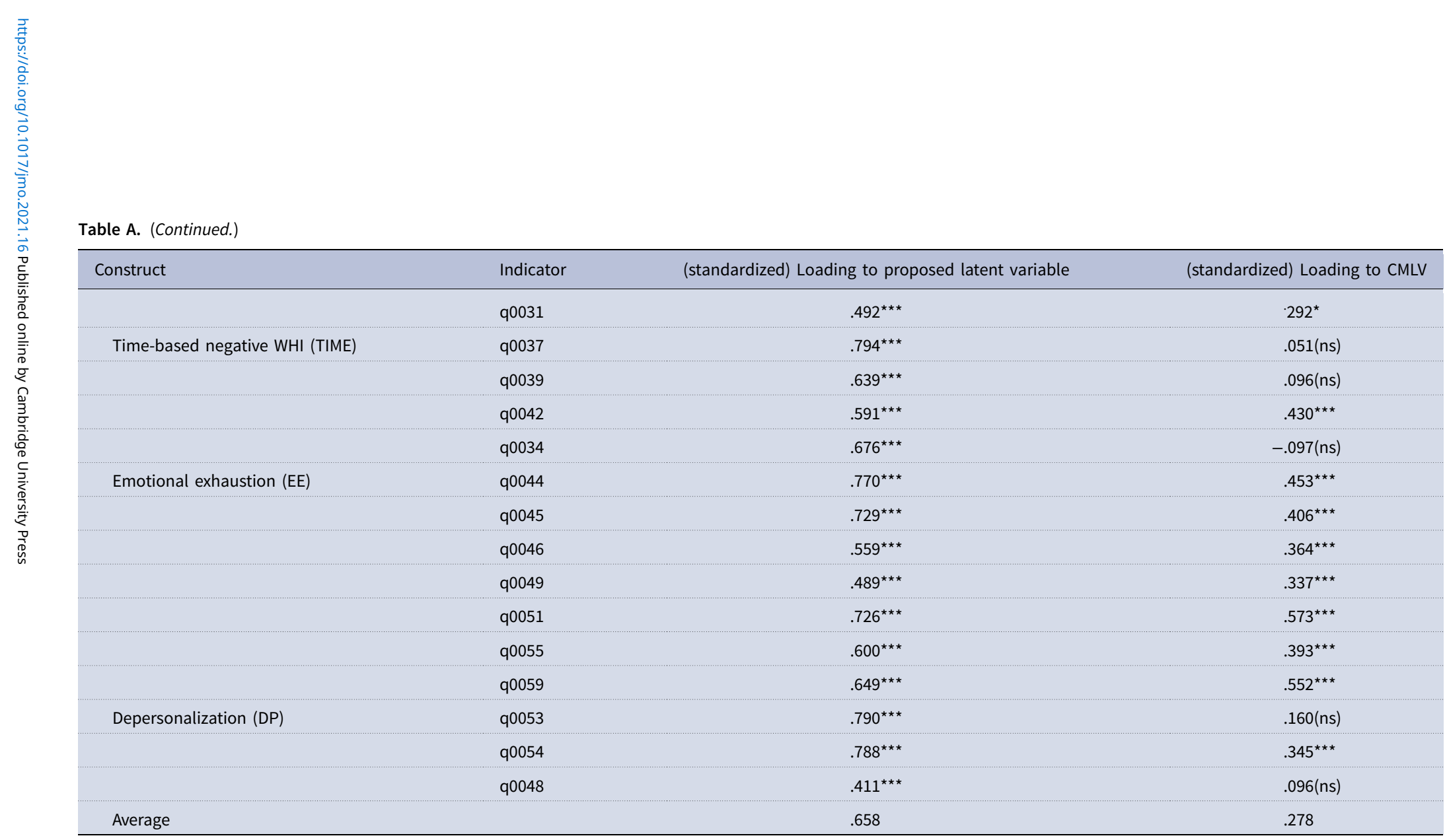

CMLV, Common method latent variable.

${ }^{\star} p<05 ;{ }^{* \star} p<01 ;{ }^{* \star \star} p<001$; ns, not significant $(p \leqslant .05)$. 
Table B. Linear regression analysis generic job demands vs occupation-specific job demands

\begin{tabular}{|c|c|c|c|c|c|c|c|c|}
\hline Model & Predictor & $B$ & $p$ & $R$ & $R^{2}$ & SE & F-change & $p$ \\
\hline \multirow[t]{2}{*}{1} & WPQ & 1.19 & .000 & & & & & \\
\hline & Mental load & .14 & .279 & & & & & \\
\hline $\begin{array}{l}\text { Model } \\
\text { summary }\end{array}$ & & & & .60 & .36 & .81 & 49.22 & .000 \\
\hline \multirow[t]{5}{*}{2} & WPQ & .94 & 0.000 & & & & & \\
\hline & Mental load & .01 & .970 & & & & & \\
\hline & indirect patent care & .23 & 0.000 & & & & & \\
\hline & $\begin{array}{l}\text { facilitatory } \\
\text { relationships }\end{array}$ & -.04 & .426 & & & & & \\
\hline & patient behaviour & .18 & .005 & & & & & \\
\hline $\begin{array}{l}\text { Model } \\
\text { summary }\end{array}$ & & & & .66 & .43 & .77 & 7.40 & .000 \\
\hline
\end{tabular}

$N=178$.

Note: The hierarchical regression analyses were performed to assess whether occupation-specific demands explained additional emotional exhaustion variance beyond the generic job demands. The coefficients differ from Table 4 since these additional analyses were limited to generic and occupation-specific demands only, while the analyses in Table 4 included generic and occupation-specific job demands and resources within the same model.

Cite this article: Verhoef NC, De Ruiter M, Blomme RJ, Curfs EC (2021). Relationship between generic and occupation-specific job demands and resources, negative work-home interference and burnout among GPs. Journal of Management \& Organization 1-29. https://doi.org/10.1017/jmo.2021.16 